\title{
Decision support framework for the regional facility location and development planning problem
}

\section{David Kik $^{1}$ (D) Matthias Gerhard Wichmann ${ }^{2}$ (D) Thomas Stefan Spengler ${ }^{1}$ iD}

Accepted: 27 May 2021 / Published online: 23 June 2021

(C) The Author(s) 2021

\begin{abstract}
Location choice is a crucial planning task with major influence on a company's future orientation and competitiveness. It is quite complex, since multiple location factors are usually of decision-relevance, incomparable, and sometimes conflictual. Further, ongoing urbanization is associated with locational dynamics posing major challenges for the regional location management of companies and municipalities. For example, respecting urban space as location factor, a scarcity growing over time leads to different assessment and requirements on a company's behalf. For both companies and municipalities, there is a need for location development which implies an active change of location factor characteristics. Accordingly, considering locational dynamics is vital, as they may be decisive in the location decisionmaking. Although certain dynamics are considered within conventional Facility Location Problem (FLP) approaches, a systematic consideration of active location development is missing so far. Consequently, they may propagate long-term unfavorable location decisions, as major potentials associated with company-driven and municipal development measures are neglected. Therefore, this paper introduces a comprehensive decision support framework for the Regional Facility Location and Development planning Problem (RFLDP). It provides an operationalization of development measures, and thus anticipates dynamic adaptations to the environment. An established multi-criteria approach is extended to this new application. A complementary guideline ensures its meaningful applicability by practitioners. Based on a real-life case study, the decision support framework's strength for practical application is demonstrated. Here, major advantages over conventional FLP approaches are highlighted. It is shown that the proposed methodology results in alternative location decisions which are structurally superior.
\end{abstract}

Keywords Facility location problem - Systematic location development $\cdot$ Multicriteria decision making · Empirically sound guideline $\cdot$ Case study

David Kik

d.kik@tu-braunschweig.de

Extended author information available on the last page of the article 
JEL Classification L60 $\cdot$ R30

\section{Introduction}

Every company, independent of its size and sector, is faced at least once with the question to select a location fitting to its business purpose. The decision arises, e.g., if a company is found or an existing facility is relocated. Basically, the decision on a location is a crucial planning task with major impact on the future competitiveness and success of companies (Owen and Daskin 1998). Also, it is a complex task since companies pursue multiple, usually incomparable and conflicting objectives at once (Farahani et al. 2010; Current et al. 1990; ReVelle et al. 1981). Due to the strategic importance and high complexity of a Facility Location Problem (FLP), a systematic decision support is indispensable.

Furthermore, the ongoing urbanization confronts, both companies and municipalities, with extensive challenges in their regional location management, especially with locational dynamics. For example, due to the increasing population influx and the scarcity of space in urban areas at the same time (United Nations 2018), there is a company-driven as well as municipal need to develop locations by realizing sustainable spatial concepts. As a result, characteristics of location factors which are considered as relevant for location decisions are changing over time (e.g., space availability). This also holds for location requirements, e.g., due to urbanization. Therefore, companies and municipalities must develop locations proactively. For example, retail companies located in cities are working on transformations from initially single-level retail stores to integrated multi-level complexes with spaces for sales, living and parking. Municipalities, for instance, are gradually digitizing existing physical infrastructures or implement new mobility concepts towards a connected and smart city. This has an impact on numerous location factors in order to ensure sustainability and long-term competitiveness. Thus, within a company's FLP, it is crucial to anticipate over-time locational dynamics when deciding on locations.

Generally, three types of locational dynamics may influence location decisions of companies. First, the location requirements of a company are expected to change over time. Usually, they tend to increase due to, e.g., technological, organizational, or economical improvements. Second, characteristics of location factors are expected to change over time as well. This is due to realization of company-driven and municipal measures for location development which imply an active change of a location factor's characteristic over time. Third, interactions between companydriven and municipal measures may arise when jointly developing a location. The locational dynamics are explained using an illustrative example for a location decision (see Fig. 1).

In Fig. 1, the columns refer to three location alternatives, from which one is to be selected. The rows refer to five decision-relevant location factors, according to which the location alternatives are assessed. The cells indicate whether a location initially $\left(t_{o}\right)$ or in future $\left(t_{1}\right)$ meets the requirements. Besides, the framing of cells depicts whether a realization of development measures is necessary to fulfil the requirements. The three locational dynamics are incorporated as follows. Firstly, 


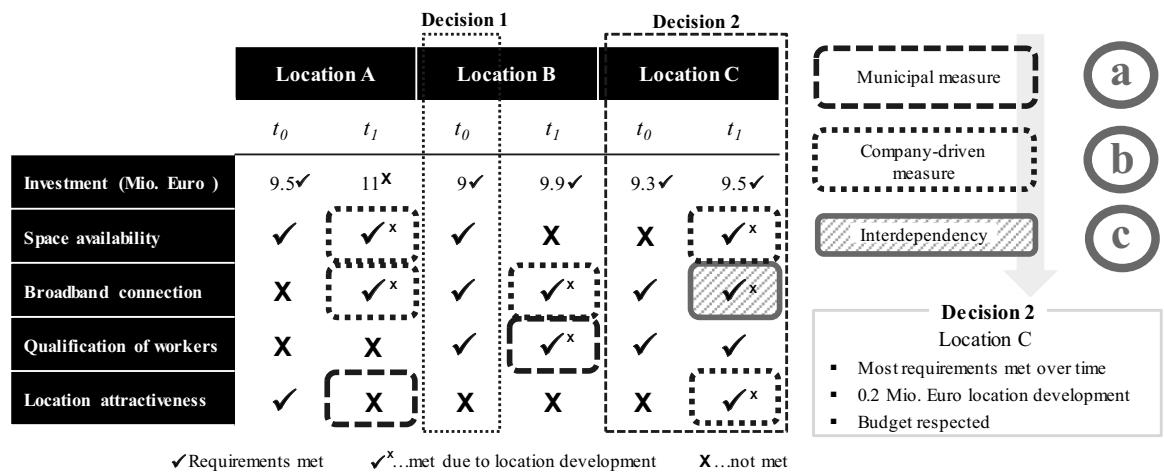

Fig. 1 Illustrative example: locational dynamics due to the realization of development measures

with respect to changing location requirements over time, the requirements on the broadband connection of a location are significantly higher in future than initially. This applies to all three location alternatives. Secondly, location factor characteristics change over time due to municipal and company-driven measures. On the one hand, municipalities develop locations within their area of influence to offer companies attractive conditions and to remain their competitiveness within a region (Tretter 2017). However, since municipalities usually do not have precise knowledge about individual needs of settling companies, the realization of municipal measures does not necessarily result in a fulfillment of a company's requirements. This can be seen in the location attractiveness at location A (see Fig. 1a). On the other hand, companies are able to develop locations in line with their requirements, and thus usually develop locations proactively and purposefully. The fulfillment of initially unattained requirements of a company is ensured as depicted for broadband connection at both location A and location B (see Fig. 1b). Thirdly, interactions between municipal and company-driven measures may occur. By a combination of appropriate measures, initially unattained requirements may be fulfilled as depicted for broadband connection at location $\mathrm{C}$ (see Fig. 1c). As a result, an interaction between companies and municipalities is beneficial and indispensable in regional location and development planning.

The influence of locational dynamics on location decisions is crucial as will be depicted in the following. Here, two fundamentally different approaches to making decisions in FLPs are compared. Firstly, a conventional approach is considered, neglecting the three types of locational dynamics. This usually applies to existing FLP approaches from literature. Thus, only actual company's requirements and location factor characteristics are considered. Assuming the same importance for all location factors, the company would decide for location B, since it meets most of the actual requirements and has the lowest investment requirement. Secondly, a location decision is made using an approach, where all exogenous dynamics as well as the decision-dependent degrees of freedom in company-driven measure planning are considered. Thus, the actual $\left(t_{0}\right)$ as well as the future $\left(t_{1}\right)$ requirements and location factor characteristics are considered. If all location factors have the same 
importance, location $\mathrm{C}$ is selected. In doing so, a company-driven measure is allocated to develop given conditions at location $\mathrm{C}$ as required. The company envisages up to 0.4 Mio. Euro measure budget. However, 0.2 Mio. Euro are enough to fulfill the company's requirements. This is considered as a purposeful dimensioning of company-driven development measures. As a result, location $\mathrm{C}$ meets the most requirements over time and its selection as well as development requires the lowest investment. Location B fulfils the requirements as best as possible at $t_{0}$, but not in the long-term due to locational dynamics over time. As a result, location B turns out to be unfavorable in the long-term compared to location $\mathrm{C}$. Therefore, in general, conventional FLP approaches may propose unfavorable location decisions, since relevant location developments are neglected (Kik et al. 2018a, b; Richter 2017).

So far, a general planning approach for an integrated location selection and development is missing in literature. Here, especially the opportunity for a systematic planning of company-driven measures under consideration of municipal measures is missing. In this paper, an adequate decision support framework for the Regional Facility Location and Development planning Problem (RFLDP) is introduced. The framework consists of an established planning model which can take multiple criteria into account as well as a complementary guideline which contains empirically sound best practices for the collection and operationalization of relevant data. Based on a case study from reality, the validity and advantages of the framework are examined ex-post, since it usually takes several years until a decision-maker can judge his satisfaction on a location decision which is used as an essential reference. The decision support framework shows major potentials for a support of future corporate decisions in regional location selection and development.

The remainder of the paper is structured as follows: In Sect. 2, the state-of-the-art in terms of location decision-making is given from, both a practical and literature point of view, to identify needs for action. In Sect. 3, the decision support framework for the RFLDP is introduced which is an interplay of a mathematical planning model and a complementary guideline. Section 4 focusses the examination of obtained decision recommendations which are derived through the practical application of the decision support framework within a real-life case study. In Sect. 5, managerial implications are given. The paper closes with a summary and an outlook on further research in Sect. 6.

\section{State-of-the-art}

\subsection{Regional location decisions in practice}

Location decisions are typically carried out by companies. To identify needs and to clarify corresponding requirements towards a decision support, it is vital to understand the regional location decision-making of companies. To this end, seven cases from reality are investigated. Each is either a settlement or relocation of a company within a German region. Further, each company made the location decision in recent past. 
As a representative sample, special emphasize is given to heterogeneity of the considered companies in terms of their organizational size and sector affiliation. To gain information, in-depth interviews were conducted with locational responsibilities from both small and medium-sized enterprises (SMEs) and corporates. On behalf of SMEs, the interviewees were the respective chief executive officers (CEOs). From corporates, the interviewees were relevant employees with a management function for, e.g., a certain department, project or a whole plant situated at a certain location. Further, the considered companies are affiliated to distinct sectors, e.g., automotive, metal and systems engineering, logistics, IT, etc.

To conduct the in-depth interviews in a standardized way, an appropriate questionnaire was prepared. It contained the following three guiding questions which were answered based on the companies' experiences in regional location planning and development:

1. How do companies decide on locations and which (decision-supporting) methods are used for this purpose?

2. How are location decisions prepared and, respectively, what does the corresponding decision-making process look like?

3. What role do municipal actors play in the regional location decision-making of companies?

To discuss the latter question, also standardized in-depth interviews were conducted with economic development organizations. Usually, they are a primary contact for settlement and relocation issues of companies (Wagner-Endres 2020). Eight economic development organizations are considered. In terms of heterogeneity, the considered organizations operate economic development on different layers (e.g., municipal, regional, state) and further within two different German regions. The interviewees were relevant experts who advice companies on location inquiries. Based on their experience and expertise, it is investigated how economic development organizations operate when companies inquire for settlements and relocations.

Overall, the considered companies' regional settlement and relocation projects from reality had two things in common. First, at the decision point of time, each company considered own possibilities to actively develop selected conditions at potential locations. Second, each company considered multiple objectives as decision-relevant when making decisions in the regional location planning and development (i.e., between 9 and 19 objectives).

\subsection{Literature overview}

The relevant state-of-the-art from a literature point of view is depicted in three steps. Firstly, the current FLP literature is characterized based on a structural framework. Secondly, main characteristics of the regional location selection and development are presented. Thirdly, particular characteristics are compared to known FLP approaches from literature. 
FLPs represents the core within the research field of Location Science which became of immense interest for researchers as well as practitioners over time. In FLPs, the main aim is to determine at least one location which is considered as suitable according to a decision-maker's individual requirements and restrictions (e.g., resources) to which a location decision is subject of (Laporte et al. 2015). In the past decades a vast variety of continuous, network-based and discrete planning approaches was developed to FLPs (Arabani and Farahani 2012; Nickel et al. 2005).

Existing FLP approaches can be classified according to five structural characteristics and further the number of decision criteria. Structural characteristics are distinct following five criteria (Current et al. 1990). The first criterion is the number of locations sought. It is differentiated between single and multiple locations. The second criterion refers to the capacity of facilities (e.g., production capacities). A differentiation is made between limited and unlimited capacities. The third criterion addresses the decision space. It contains either a finite number of potential locations (discrete decision space) or allows to locate a facility anywhere within a given plane (continuous decision space). The fourth criterion is the type of parameters which may be either deterministic or stochastic. The fifth criterion addresses the considered number of periods. Either one or multiple periods may be considered, and thus a differentiation is made between static and dynamic FLP approaches, respectively. Further, in case of latter, parameters may vary over time. Regarding the number of decision criteria considered, FLP approaches address either a single criterion or multiple criteria simultaneously (Arabani and Farahani 2012). Single-criteria approaches aim to optimize a respective objective function value (e.g., maximizing capital value, minimizing transportation costs, etc.). In case of multi-criteria approaches, location decisions are supported which are either based on a comparison of multiple criteria or the optimization of multiple objective function values. Herein one usually deals with incommensurability and further conflicts amongst decision criteria.

In contrast to single-criteria approaches, multi-criteria approaches are superior in terms of identifying compromise solutions when facing a multitude of distinct and conflicting criteria. Usually, FLPs are multi-criteria decision problems, and thus multi-criteria decision making (MCDM) approaches are promising as a decision support for the location selection (Farahani et al. 2010). Therefore, approaches from the branch of MCDM received particular attention in Location Science, resulting in a vast variety of applications to FLPs. Comprehensive literature overviews are given by, e.g., Arabani and Farahani (2012), Farahani et al. (2010), Hekmatfar and SteadieSeifi (2009), Nickel et al. (2005), Malczewski and Ogryczak (1996), Malczewski and Ogryczak (1995), and Current et al. (1990).

In literature, existing MCDM approaches to FLPs are divided into three streams. The first stream comprises multi-attribute decision making (MADM) approaches which are used to select locations from exclusively a discrete set of location alternatives by comparing multiple decision-relevant criteria (i.e., attributes). The second stream comprises multi-objective decision making (MODM) approaches which are applied to select or design locations, especially in case of conflicting objectives, many alternatives, and mathematically constrained solution spaces (Wallenius et al. 2008). In contrast to MADM approaches, those of MODM can be generally used for decision problems with discrete as well as continuous decision components (Ehrgott 
2005; Ignizio and Romero 2003; Stewart 1992; Zimmermann and Gutsche 1991; Hwang and Yoon 1981; Hwang and Masud 1979). Usually, multi-objective decision problems are transformed into single-objective ones by means of scalarization techniques, e.g., reference point or constraint methods (Ehrgott 2005). A common scalarization technique, based on reference points, is the Goal Programming (GP) method introduced by Charnes et al. (1955) and further developed by numerous authors (e.g., Charnes and Cooper 1961; Ijiri 1965; Lee 1972; Ignizio 1976; Romero 2001; Ignizio and Romero 2003). Comprehensive overviews on relevant GP developments and trends are given in, e.g., Caballero et al. (2009), Barichard et al. (2009), Abdelaziz (2007), Tanino et al. (2003), Trzaskalik and Michnik (2002), and Aouni and Kettani (2001). A third stream comprises hybrid approaches to FLPs which either represent a combination of MCDM approaches with each other or MCDM approaches with other techniques, e.g., geographic information systems (GIS) from the research field of geography and commonly used for gathering and analyzing spatial data (Malczewski and Rinner 2015; Malczewski 2010; Wang et al. 2009). For further general method combinations against the background of MCDM, reference is made to Marttunen et al. (2017).

Considering the three streams of MCDM based FLP approaches, relevant articles were examined. They were identified through structured search inquiries of the literature databases Scopus and Google Scholar. The search inquiries included a suitable combination of varying keywords, both from the field of MCDM and FLP. A period from 1973 to 2021 was considered. The identified articles were published in journals related to the field of business administration, especially in the subfields Production, Operations Research and Business Informatics. The most prominent journals were European Journal of Operational Research, Omega, Computers and Industrial Engineering, Computers and Operations Research and Decision Sciences. As a result, a total of 252 existing MCDM based FLP approaches are identified through the structured search and examined in more detail. Overall, it is observed that the stream of MODM represents the largest part with $59 \%$ of all identified approaches. Frequently applied to FLPs are GP approaches, e.g., in its standard, weighted and lexicographic variation. Moreover, so-called generating techniques are applied to FLPs which initially aim to exactly determine or to approximate the set of efficient solutions from which the most preferred one is then chosen (Malczewski and Ogryczak 1995). For example, weighting and ( $\varepsilon-$ ) constraint methods. The MADM stream represents $26 \%$ of all approaches. Here, the Analytic Hierarchy Process (AHP) and its further development, the Analytic network Process (ANP), as well as the Preference Ranking Organization METHod for Enrichment of Evaluations (PROMETHEE) I and II are commonly applied to FLPs. Hybrid approaches account for $15 \%$ of all approaches. Primarily there exist combinations of different MCDM approaches with GIS techniques. Furthermore, hybrid approaches, comprised of MADM and MODM methods, are also common in FLPs (e.g., combinations of AHP or ANP with GP).

As usually true for FLPs in literature, the decision problem within the regional location selection and development is multi-criteria as well. In order to evaluate the suitability of existing MCDM approaches as a decision support, the given decision problem is classified in more detail below. This is done based on the five structural 
characteristics introduced before. First, the choice of a single location is intended. Second, there are no relevant capacities to consider. Third, the decision space is neither exclusively discrete nor continuous, but is a combination of both decision components. Although the location selection is made from a discrete set of alternatives, decisions on location development require an adequate dimensioning of each company-driven measure, and thus are continuous in nature. Measure dimensioning refers to the determination of a concrete measure intensity. For example, if a company intends a certain measure for property expansion at a potential location by up to $1000 \mathrm{sqm}$. At least, the company must decide on an appropriate amount of sqm which have to be realized ultimately in order to meet its own requirements. Fourth, parameters are considered as deterministic. Fifth, a dynamic FLP with a multi-period planning horizon is considered, since locational dynamics over time may have a significant influence on a company's location decision.

Having classified the decision problem within the regional location selection and development, it can be concluded that MADM approaches seem to be rather inappropriate as a decision support. This is justified by underlying continuous decision components in measurement planning for location development, whose consideration is crucial. Thus, MODM approaches are promising as a suitable decision support, since they are capable in considering both continuous and discrete decision components at the same time. Moreover, depending on the possibilities of a company, in real-life FLP there may be large planning instances. Especially, with regard to the number of criteria, whose characteristics are to be influenced by companydriven measures and the number of potential locations. As a result, for practitioners, there is often an unmanageable number of possibilities in the allocation of companydriven measures to location alternatives. In general, MODM approaches are capable of handling such a combinatorial complexity through computations.

For this reason, selected MODM approaches to FLPs existing in literature are presented below. For example, Kınay et al. (2019) developed a lexicographic GP (LGP) model and an $\varepsilon$-constraint model in order to evaluate their suitability for a shelter location problem in the context of preventive disaster management. Considering multiple capacitated shelters, stochastic parameters and a static planning horizon, both multi-objective models support discrete location decisions under consideration of three objectives. Karatas (2017) introduced a weighted GP (WGP) model to a FLP where multiple capacitated facilities have to be located whilst considering deterministic parameters within a static planning horizon. The location decisions are discrete, with the aim of minimizing deviations from the facilities demand coverage and capacities as well as the allocated budget. Xu et al. (2016) developed a bi-objective model to a hydropower station FLP with multiple non-capacitated hydropower facilities, while taking into account fuzzy parameters in a multi-period planning horizon. Discrete location decisions are made in order to minimize total cost and maximize safety at the same time. San Cristóbal (2012) provided a standard GP model to a renewable energy FLP where multiple non-capacitated facilities have to be located when facing deterministic parameters in a static planning horizon. The model supports discrete location decisions in order to minimize deviations facing a total of seven ecological, economic and social objectives. Kanoun et al. (2010) developed a WGP formulation for an emergency service FLP where a single 
location for a capacitated service station is sought, facing deterministic parameters within a static planning horizon. Here, discrete location decisions are aided in order to minimize the deviations from overall 15 objectives, some of which are conflicting in nature (e.g., proximity to industrial firms versus response time). Pati et al. (2008) presented a WGP model for reverse logistics system planning with the focus on a FLP, in which multiple non-capacitated facilities have to be located within a given reverse distribution network. Herein, parameters are assumed to be deterministic within a static planning horizon. The supported location decisions are discrete in nature, aiming to minimize three decision-relevant economic, social and qualityrelated objectives. Dias et al. (2008) proposed a multi-objective memetic algorithm to FLPs considering multiple both capacitated and non-capacitated facilities in a deterministic and multi-period environment. The FLPs are bi-objective where discrete location decisions in terms of an opening, closing and reopening of factories at locations over time have to be supported. Melachrinoudis and Min (2000) proposed a multi-objective model formulation to a FLP where multiple plant-warehousing facilities have to be relocated, taking into account capacities under the assumption of deterministic parameters within a multi-period planning horizon. Herein, discrete location decisions with regard to an opening and closing of facilities at locations are supported in order to maximize both total profit as well as location incentive and to minimize the total transit time to customers. Badri et al. (1998) introduced a LGP model to a fire station FLP, in which locations for multiple non-capacitated stations have to be identified in a deterministic environment with a static planning horizon. The model supports discrete location decisions in order to minimize deviations from overall 11 objectives where some of them are conflicting (e.g., minimize operating costs versus maximize service). Min and Melachrinoudis (1996) provided a WGP model to an international FLP, in which multiple locations for capacitated facilities are sought, under consideration of stochastic parameters within a multi-period planning horizon. The model supports the selection of locations from a discrete set of alternatives, aiming to minimize deviations from after-tax profits, intangible benefits, and general risks.

Overall, it is observed that a multitude of MCDM method applications can be found in relevant literature to provide a decision support on various FLPs. Here, it is further noticed that most of these applied methods belong to the methodological string of MODM. Within some MODM based FLP approaches, certain exogenous dynamics are already addressed given a dynamic environment. Thus, location decisions are occasionally supported under consideration of over-time volatile characteristics of decision-relevant objectives. Although these MODM approaches lead to apparently meaningful results for the respective FLP considered, however, possibilities for an active development of locations remain neglected so far.

\subsection{Conclusion and requirements}

Based on the examined state-of-the-art with respect to, both regional location decisions in practice (Sect. 2.1) and FLP approaches identified in literature (Sect. 2.2), 
a conclusion is drawn and main requirements towards a decision support for the RFLDP are specified below.

The conclusions are drawn in a structured way by following the three guiding questions raised in Sect. 2.1. Firstly, it can be noted that decisions, which were made in regional location planning and development by the interviewed companies, mostly lack a methodologic and objective solid base. Although multiple objectives were considered by the companies, not even the simplest multi-criteria method was used as decision support (e.g., utility analysis). Further, the manager's affect (i.e., heuristic gut feeling) influenced location decisions. This particularly applies to SMEs where, e.g., a CEO's bond to a certain location may be decisive. Especially, decisions regarding company-driven location developments are usually subject to the heuristic gut feeling, and thus are not made in a systematic manner in practice. Even though an affective decision-making can result in good decisions within a complex decision environment (Mikels et al. 2011; Hämäläinen 2004), in RFLDP, it shall be relied on an analytical procedure when making strategic decisions of critical importance. Altogether, the findings from practice coincide with those from literature where no suitable RFLDP model formulation exists so far.

Secondly, the decision-making of the considered companies in regional location planning and development in practice is not well-structured. This is particularly true for SMEs, where CEOs lack experience with respect to location issues and, further, there are insufficient financial means to engage relevant consulting firms.

Thirdly, in practice, location-seeking companies strongly depend on municipal actors when collecting data, especially on economic development organizations as relevant data suppliers. However, to inquire an appropriate contact may be time-consuming and challenging for companies. The main reason for this is that companies usually lack knowledge on how economic development is organized within regions. Instead of a uniform organizational structure of economic development, there are rather disparities between and within regions, particularly concerning the vertical (e.g., municipal, county or regional layer) and horizontal organization (e.g., part of a municipal administration or autonomous offices). In addition, there are inter- and intraregional differences on how an economic development organization perceives its contribution to a region, and thus on which tasks it focuses on as well as how the tasks are distributed along the vertical and horizontal (Wagner-Endres 2020).

Based on the findings, two main requirements towards a decision support for the RFLDP are derived. On the one hand, a suitable decision support must provide an anticipation of location developments, and thus must focus on dynamic location planning. Hereby, an allocation and dimensioning of company-driven measures for the determination of an optimal strategic development measure plan must be supported. Hence, an adequate planning model must be developed whose formulation provides a support for both continuous decisions in measure planning and discrete decisions in location selection. To this end, new paths in model development must be taken.

On the other hand, a suitable decision support must additionally provide guidance for location-seeking companies which aims to structure the RFLDP decisionmaking process in a meaningful manner. Given the challenging data situation, such a guideline must provide best practices on where to gather and how to operationalize 
decision-relevant data in a practical way. Thus, the guideline intends to contribute to the fulfillment of data requirements of the planning model and to ensure its fruitful applicability by practitioners.

With development of the decision support framework for the RFLDP, both a relevant research gap in Location Science and main hurdles arising for companies in practice, are addressed.

\section{Development of a decision support framework for the regional facility location and development planning problem}

The developed decision support framework for the RFLDP is composed of two interplaying components. The first component is a planning model which aims to provide an objectively sound basis for decision-making. To this end, an established MODM model formulation is extended to the new application. The model formulation provides an opportunity to operationalize relevant location developments. The second component is a complementary guideline which aims to structure a company's decision-making purposefully and to foster the communication with relevant municipal actors to close information gaps in early phases. This is achieved by providing empirically sound best practices to companies on how to gather und operationalize data.

The decision support framework is developed in a generic manner, and thus support can be basically given to any type of company facing the RFLDP, irrespective of its size and sector affiliation.

\subsection{Planning model}

\subsubsection{Problem setting and modelling approach}

A simplified planning situation in the RFLDP is exemplary depicted in Fig. 2.

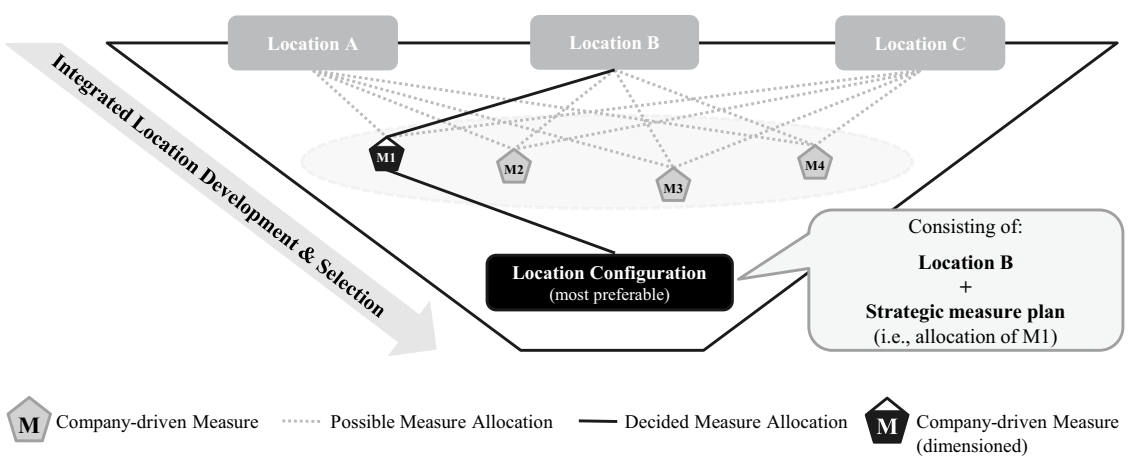

Fig. 2 Integrated RFLDP planning task 
It is an integrated planning task which includes decisions in, both location selection and development. According to the example in Sect. 1, the company envisages four measures (M1-M4), each of which is intended to develop the characteristics of decision-relevant location factors.

Through allocation to a certain location and a simultaneous dimensioning of each measure, a strategic measure plan is determined for the long-term optimal development of each location. Herein, municipal development measures at potential locations are considered. Accordingly, an optimal location configuration is determined for each potential location. In this sense, a location configuration is referred to a combination of a potential location and a respective strategic measure plan for its long-term optimal development. As a result, the most preferable location configuration is chosen which meets the decision-maker's individual location requirements as best as possible.

To formalize the planning situation, an established WGP formulation model is used. Within the WGP, multiple qualitative and quantitative objectives can be considered within a single objective function. The objective function is a distance function which aims to measure the distance between a feasible solution and a reference point indicated by the decision objectives' targets set by a decision-maker a priori (Ehrgott 2005). Herein, the optimal solution is referred to the minimum distance. The WGP's distance function is based on the $L_{1}$-metric (i.e., sum norm) which implies a decision maker's interest in an average fulfillment of the objectives' targets (Jones and Tamiz 2010). Thus, the $L_{1}$-metric appropriately reflects the real-life decision-making where managers are interested in comparing objectives directly and analyzing trade-offs. In WGP, target deviations are additionally penalized according to individual preferences of managers. Thus, the aim of WGP is to minimize the weighted sum of unwanted deviations from the objectives' targets.

The WGP meets special requirements and has three main advantages compared to other MODM approaches. Firstly, WGP is subject to the satisficing principle which is usually considered as more convenient than rational optimizing in multi-objective problems, since WGP models can determine a feasible compromise solution considering conflicting objectives (Ehrgott 2005; Simon 1957). Secondly, WGP models can handle a vast number of objectives simultaneously (i.e., $>3$ objectives), and thus an optimal solution is usually determined in an acceptable computation time (Malczewski and Ogryczak 1995). Thirdly, the WGP setting is easily accessible and straightforward for managers who usually lack knowledge and experience in using mathematical models (Tamiz et al. 1998).

\subsubsection{Model assumptions}

The integrated planning task within the RFLDP is based on eight assumptions which are depicted below.

1. The decision-maker can distinguish between different types of objectives and is able to reflect preferences regarding them. The preferences can be transformed into appropriate weights. 
2. The decision about the location selection is made only once in period $t_{0}$ and not changed during the planning horizon.

3. The planning horizon is finite and includes $T$ discrete periods.

4. Company-driven measures can be allocated more than once throughout the entire planning horizon. They are realized at the beginning of a period and have an immediate effect on the related location factors. That also holds for municipal measures in location development.

5. For company-driven measures, a positive linear correlation between the amount of investment and measure impact is assumed. For example, if the amount of investment is increased by $20 \%$ compared to a basic level, the measure impact also increases by $20 \%$.

6. Follow-up costs of measures allocated in period $t$ incur in subsequent periods $t+1$ until the end of the planning horizon.

7. The utility correlation between company-driven and municipal measures for location development is additive. Since interdependencies may occur if and only if redundancies, and thus non-additive correlations between company-driven and municipal measures exist. Therefore, non-linearities are not considered.

8. All parameters are assumed to be deterministic and known by the decision-maker.

\subsubsection{Model formulation}

A suitable RFLDP model formulation is presented in the following. To this end, the notation for relevant indices, parameters, and decision and auxiliary variables is given in Table 1 .

The model formulation is based on established WGP formulations given by, e.g., Jones and Tamiz (2010), Mirrazavi et al. (2001), Romero (1991), Yu (1985), Cohon (1978), or Zimmermann and Gutsche (1991). Overall, the model consists of an objective function and 14 constraints.

$$
\text { Minimize } \sum_{i=1}^{I} \sum_{j=1}^{J} \sum_{t=0}^{T}\left(w_{i, t}^{+} \cdot d_{i, j, t}^{+}+w_{i, t}^{-} \cdot d_{i, j, t}^{-}\right) \text {. }
$$

The objective function (1) aims to minimize the weighted sum of unwanted deviations from the targeted characteristics for all objectives $i$ over all periods. In terms of target deviations, a distinction is made between positive deviations $d_{i, j, t}^{+}$ and negative deviations $d_{i, j, t}^{-}$. Depending on the type of objective $i$, at least one deviation is considered as unwanted, and thus is penalized by a corresponding weight $w_{i, t}^{+}$or $w_{i, t}^{-}$greater or equal zero. The weights represent the decision-maker's preferences regarding objective $i$. Further, they may vary over time.

The 14 constraints of the model are grouped into five categories. The first category of constraints addresses the selection of a location. Here, constraint (2) ensures that exactly one location $j$ is selected. 
Table 1 Model notation

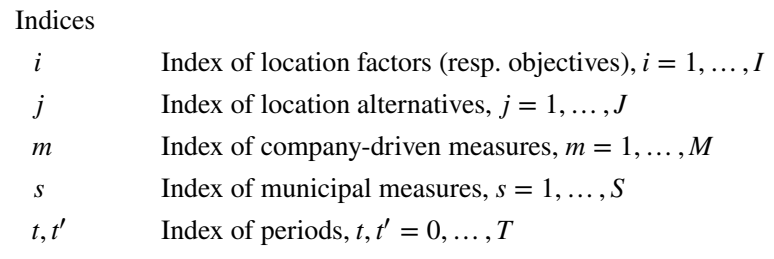

Parameters

$a_{i, j} \quad$ Characteristic of objective $i$ at location $j$ in period $t_{0}$

$A_{i, t}^{\min } \quad$ Minimum threshold for characteristic of objective $i$ in period $t$

$A_{i, t}^{\max } \quad$ Maximum threshold for characteristic of objective $i$ in period $t$

$b_{i, t} \quad$ Targeted characteristic of objective $i$ in period $t$

$B \quad$ Overall budget available for location set-up and development

BigM Sufficiently large number

$C E_{i, j, m} \quad$ Impact of company-driven measure $m$ at location $j$ on objective $i$

$d_{t} \quad$ Discount rate in period $t$, with $d_{t}=(1+h)^{-t}$

$F C_{j, m, t} \quad$ Follow-up costs of company-driven measure $m$ at location $j$ in period $t$

$h \quad$ Calculatory interest rate

$I C_{j} \quad$ Investment requirement for setting up location $j$

$I D_{j, m, t} \quad$ Investment requirement for allocating and dimensioning a company-driven measure $m$ for developing location $j$ in period $t$

$M E_{i, j, s, t} \quad$ Impact of municipal measure $s$ on objective $i$ at location $j$ in period $t$

$w_{i, t}^{+} \quad$ Weight of a positive target deviation regarding objective $i$ in period $t$

$w_{i, t}^{-} \quad$ Weight of a negative target deviation regarding objective $i$ in period $t$

Variables

$d_{i, j, t}^{+} \quad$ Positive target deviation regarding objective $i$ in period $t$ at location $j$

$d_{i, j, t}^{-} \quad$ Negative target deviation regarding objective $i$ in period $t$ at location $j$

$D_{i, j, t} \quad$ Buffer variable compensating the gap between actual and targeted characteristic of objective $i$ at location $j$ in period $t$ (if $x_{j}=0$ )

$x_{j}= \begin{cases}1, & \text { if location } j \text { is selected } \\ 0, & \text { otherwise }\end{cases}$

$y_{j, m, t} \quad$ Intensity of allocated company-driven measure $m$ to location $j$ in period $t$

$y_{j, m, t}^{\prime} \quad$ Auxiliary variable for follow-up costs of company-driven measure $m$ at location $j$ in period

$$
\sum_{j=1}^{J} x_{j}=1 .
$$

The second category of constraints encompasses the determination of target deviations $d_{i, j, t}^{+}$and $d_{i, j, t}^{-}$based on the difference of achieved and targeted characteristic of objective $i$ at location $j$ in period $t$.

$$
\begin{aligned}
& a_{i, j} \cdot x_{j}+\sum_{t \prime=0}^{t} \sum_{m=1}^{M} y_{j, m, t \prime} \cdot C E_{i, j, m}+\sum_{t \prime=0}^{t} \sum_{s=1}^{S} M E_{i, j, s, t \prime}-d_{i, j, t}^{+}+d_{i, j, t}^{-}+D_{i, j, t} \\
& =b_{i, t} \quad \forall i \in I, j \in J, t \in T .
\end{aligned}
$$


For this purpose, constraint (3) aims to identify the achieved characteristic of objective $i$ and its deviation from its time-dependent targeted characteristic $b_{i, t}$. The achieved characteristic of an objective $i$ is based on two components. The first component is the characteristic $a_{i, j}$ given in period $t_{0}$. Since the starting characteristic is only relevant for the selected location, it is multiplied by the decision variable $x_{j}$. The second component comprises its development over time which is caused by company-driven measures $m$ as well as municipal measures $s$. The overall impact of company-driven measures $m$ on objective $i$ is determined by summing the product of decision variables $y_{j, m, t^{\prime}}$ for company-driven measure and parameter $C E_{i, j, m}$. The overall impact of municipal measures $s$ on objective $i$ is determined by summing the corresponding parameters $M E_{i, j, s, t^{\prime}}$. By doing so, developments caused by companydriven and municipal measures in preceding periods $t^{\prime} \leq t$ are considered through a restricted sum from $t_{0}$ to $t$. The calculation of, both target deviations $d_{i, j, t}^{+}$and $d_{i, j, t}^{-}$, is comprised by constraints (4)-(7).

$$
\begin{aligned}
& d_{i, j, t}^{+} \leq x_{j} \cdot \operatorname{BigM} \quad \forall i \in I, j \in J, t \in T, \\
& d_{i, j, t}^{-} \leq x_{j} \cdot \text { BigM } \quad \forall i \in I, j \in J, t \in T .
\end{aligned}
$$

Constraints (4) and (5) ensure that both deviations may only take a value greater or equal zero for the selected location $j$. In order to fulfil the balance constraint (3) for unselected locations, $D_{i, j, t}$ is used as a dummy variable with a buffer function.

$$
\begin{gathered}
D_{i, j, t} \leq\left(-x_{j}+1\right) \cdot B i g M \quad \forall i \in I, j \in J, t \in T, \\
D_{i, j, t} \geq\left(x_{j}-1\right) \cdot B i g M \quad \forall i \in I, j \in J, t \in T .
\end{gathered}
$$

Constraints (6) and (7) ensure that $D_{i, j, t}$ is forced to be equal zero for the selected location $j$. For all unselected locations, $D_{i, j, t}$ may take an arbitrary value in order to keep the balance of constraint (3).

The third category of constraints encompasses the modelled interdependencies between company-driven measure allocation and dimensioning.

$$
y_{j, m, t} \leq x_{j} \quad \forall j \in J, m \in M, t \in T .
$$

Constraint (8) ensures that an allocation and dimensioning of company-driven measures $m$ is only allowed for the selected location $j$. Simultaneously, for all unselected locations, the allocation and dimensioning of company-driven measures is prohibited.

$$
y_{j, m, t}^{\prime} \geq \sum_{t \prime=0}^{t \prime<t} y_{j, m, t \prime} \quad \forall j \in J, m \in M, t \in T .
$$

Constraint (9) sets a lower bound to the cumulative intensity of company-driven measure $m$ in location $j$ obtained until period $t$, depicted in auxiliary variable $y_{j, m, t}^{\prime}$. Since company-driven measure $m$ might be implemented over several periods or 
even more than once, it is necessary to keep track of the cumulated measure intensity. This is done in constraint (9) by means of a restricted sum of the decision variable for company-driven measure allocation and dimensioning $y_{j, m, t}$ from period $t_{0}$ to $t$.

The fourth category of constraints contains requirements with respect to the integrated location and development planning.

$$
\begin{aligned}
& a_{i, j} \cdot x_{j}+\sum_{t \prime=0}^{t} \sum_{m=1}^{M} y_{j, m, t \prime} \cdot C E_{i, j, m}+\sum_{t \prime=0}^{t} \sum_{s=1}^{S} M E_{i, j, s, t \prime} \geq A_{i, t}^{\min } \cdot x_{j}-\operatorname{BigM} \cdot\left(1-x_{j}\right) \\
& \forall i \in I, j \in J, t \in T, \\
& a_{i, j} \cdot x_{j}+\sum_{t \prime=0}^{t} \sum_{m=1}^{M} y_{j, m, t \prime} \cdot C E_{i, j, m}+\sum_{t \prime=0}^{t} \sum_{s=1}^{S} M E_{i, j, s, t \prime} \leq A_{i, t}^{\max } \cdot x_{j}+B i g M \cdot\left(1-x_{j}\right) \\
& \forall i \in I, j \in J, t \in T .
\end{aligned}
$$

In constraints (10) and (11), the fulfilment of hard constraints is considered. On the one hand, constraint (10) ensures that the achieved characteristic of objective $i$ in period $t$ must be at least equal to a minimum requirement threshold value $A_{i, t}^{\min }$. On the other hand, constraint (11) ensures that an achieved characteristic of an objective $i$ in period $t$ is at most equal to a maximum requirement threshold value $A_{i, t}^{\max }$. Given the fact that certain locations $j$ remain unselected, in both constraints the decision variable $x_{j}$ for location selection is multiplied with $A_{i, t}^{\min }$ and $A_{i, t}^{\max }$ on the right-hand side to ensure solution feasibility. A non-conformity with thresholds leads to a disqualification of an affected location $j$.

$$
x_{j} \cdot I C_{j}+\sum_{m=1}^{M} \sum_{t=0}^{T}\left(\left(y_{j, m, t} \cdot I D_{j, m, t}\right)+\left(y_{j, m, t}^{\prime} \cdot F C_{j, m, t}\right)\right) \cdot d_{t} \leq B \quad \forall j \in J .
$$

Moreover, constraint (12) ensures a compliance with the company's budget available for the set-up and development of a location. Here, the sum of investment for setting up a location $I C_{j}$ as well as investments for its development $I D_{j, m, t}$ and corresponding follow-up costs is not allowed to exceed an overall budget $B$. Facing the changes in value of $I D_{j, m, t}$ and $F C_{j, m, t}$ over time due to interest rates, these are multiplied with a discount rate $d_{t}$ to determine their net values for the decision point of time $\left(t_{0}\right)$. Besides, since follow-up cost are based on the cumulative intensity of implemented measures, the follow-up costs are multiplied by $y_{j, m, t}^{\prime}$ (c.p. constraint (9)).

The fifth and last category of constraints addresses the model's main system constraints.

$$
\begin{gathered}
x_{j} \in\{0,1\} \quad \forall j \in J, \\
y_{j, m, t} \in[0,1] \quad \forall j \in J, m \in M, t \in T,
\end{gathered}
$$




$$
d_{i, j, t}^{+}, d_{i, j, t}^{-}, y_{j, m, t}^{\prime} \geq 0 \quad \forall i \in I, j \in J, m \in M, t \in T .
$$

Constraint (13) defines the decision variable $x_{j}$ for location selection as binary, whereas constraint (14) specifies the decision variable $y_{j, m, t}$ for company-driven measure allocation and dimensioning as continuous. Besides, constraint (15) defines the two deviation variables as well as the auxiliary variable for follow-up costs $y_{j, m, t}^{\prime}$ as non-negative.

Concluding, the objective function (1) and all constraints (2)-(15) within the model formulation are exclusively linear. In addition, relevant decision and auxiliary variables are partially continuous. Hence, the planning model presented is classified as a mixed-integer linear program (MILP). The model formulation was implemented in the optimization software AIMMS. Practice-relevant problem instances can be solved in a matter of seconds using the GUROBI 9.0 solver.

\subsection{Guideline}

\subsubsection{Conceptual reference framework}

In the following, the conceptual reference framework of the guideline is introduced by concretizing its overall aim and explaining its structure.

The aim of the guideline is to provide empirically sound best practices to company managers who face the issue of data gathering and operationalizing within the RFLDP. Through this, a meaningful applicability of the mathematical planning model by practitioners is ensured, since information gaps can be closed in early planning. Thus, the model's data requirements are met.

The guideline is structured in three areas $(a, b$ and $c)$, each of which addresses a central data-related issue within the RFLDP. The areas are explained based on Fig. 3.

Area $a$ indicates which planning information is of decision-relevance (see Fig. 3a). A distinction is made between master data and planning data according to the planning model's indices and parameters given in Sect. 3.1.3. Planning data are subdivided in four strings of data with respect to location requirements, location assessment, location development, and other.

Area $b$ indicates where to gather decision-relevant planning information (see Fig. 3b). There are three options to do so. Firstly, managers can gather data company-internal (e.g., targets $b_{i, t}$ ). Secondly, managers can gather data company-external, i.e., through inquiries with municipal actors (e.g., municipal measures $M E_{i, j, s, t}$ ). Thirdly, managers can gather data company-internal and to a limited extent (e.g., through self-research), but must gather supplementary information from companyexternal sources (e.g., characteristics of locations $a_{i, j}$ ). In Fig. 3, the gray hatchings indicate which of the three options applies to a data type.

Area $c$ refers to best practice instructions on how decision-relevant planning information is to be gathered and how it is to be operationalized in an effective way (see Fig. 3c). In Fig. 3, numberings (1-16) refer to the best practices which are introduced step by step in the subsequent section. 


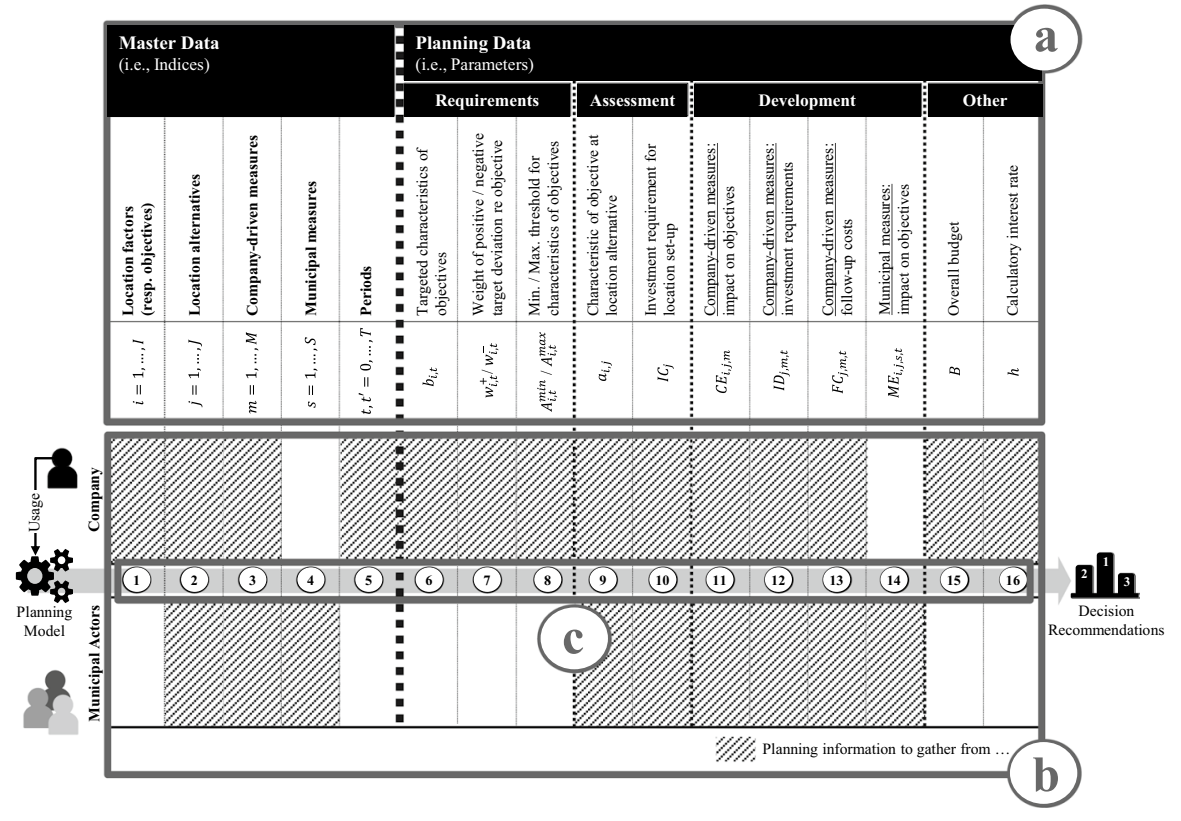

Fig. 3 Guideline: conceptual reference framework

\subsubsection{Best practice instructions}

The best practice instructions are introduced by following the main data issues which are addressed within the guideline's three areas $(a, b$ and $c)$ previously introduced.

\subsubsection{Master data}

(1) Location factors (resp. objectives), $i=1, \ldots, I$

Objectives $i$ belong to the master data. Within this scope, it is of special interest to differentiate between quantitative and qualitative objectives, i.e., measurable, and non-measurable, as well as to ensure their comparability. The finite number of objectives $I$ is usually gathered company-internal by managers.

Determining the decision-relevance of an objective strongly depends on the company's sector-specific activities and its individual aims. Beyond, the decision-relevance of objectives is frequently determined by personal motives of managers (Płaziak \& Szymańska 2014). In the past, vast research was conducted to systemize the decision-relevance of objectives in the context of FLPs (e.g., in CollMartínez and Arauzo-Carod 2017, Duboz and Kroichvili 2016, MacCarthy and Atthirawong 2003, etc.).

(2) Location alternatives, $j=1, \ldots, J$

Location alternatives $j$ belong to the master data. Within this scope, a location alternative is either a property for construction or an existing building, both spatially demarcated. The finite number of location alternatives $J$ can be 
gathered company-internal by managers to a limited extent, and thus usually through required inquiries with municipal actors for supplementary and reliable data.

To determine location alternatives through self-research, there are free options available to managers, e.g., sighting relevant online platforms which are operated by economic development organizations to promote property and building vacancies. When trying to inquire municipal actors, managers should note that there are usually major inter- and intra-regional differences regarding the organizational structure of economic development. For this reason, here it is not possible to give managers a recommendation on which particular organization should be inquired. Managers should rather make it dependent on their knowledge about a certain area of interest (i.e., a region). If no experience is given, it is recommended to inquire with higher layers.

(3) Company-driven measures, $m=1, \ldots, M$

Company-driven measures $m$ belong to the master data. Within this scope, a wide variety of measures is basically considerable, e.g., intending to improve the traffic, technical or social infrastructure at a potential location. The finite number of company-driven measures $M$ can be gathered company-internal by managers to a limited extent, and thus usually through required inquiries with municipal actors.

Whilst determining development measures, managers frequently have concrete visions which may be motivated by, e.g., the company's business aim and strategy. When consulting with relevant economic development organizations with respect to their development plans, managers are recommended to proceed as follows. At first, it shall be ensured that the realization of measures envisaged by managers is likely to be authorized by a municipality. Then, further possible needs for location development shall be determined jointly and in line with requirements of corporate managers. Here, it is important to clarify whether the development needs possibly identified are being met by municipal actors and, if not, to determine which company-driven measures can be taken.

(4) Municipal measures, $s=1, \ldots, S$

Municipal measures $s$ belong to the master data. Within this scope, a wide variety of measures is considerable which aim to create the best possible location conditions for companies. The finite number of municipal measures $S$ is usually gathered company-external by inquiring with municipal actors.

When determining municipal measures of relevance, managers shall consider that usually several municipal actors are planning location developments within a certain area of interest. Especially, by economic development organizations on different layers. Municipal measures are realized either as free decision of municipal actors or reactively to negotiations with corporate managers willing to settle or relocate within an area of interest. To gather data on the first, managers are recommended to inquire with superordinate economic development organizations (e.g., on a regional or state layer) which can indicate relevant paths of development within an area of interest. To gather data on the latter, managers are usually mediated to subordinate economic development organizations or municipalities.

(5) Periods, $t, t^{\prime}=0, \ldots, T$ 
Planning periods $t, t^{\prime}$ belong to the master data. Within this scope, the length of discrete periods is not relevant. The finite number of periods $T$ is usually gathered company-internal by managers.

When determining the number of periods, managers shall specify the planning horizon of interest. Herein, it is referred to a horizon of 5-10 years as a common reference in strategic planning. Managers shall pay attention on three aspects. Firstly, note that the longer the horizon, the harder the predictability of futureoriented data, and thus the higher the effort in gathering data becomes. Secondly, note that $t_{0}$ is to be considered as the starting point (i.e., decision point of time) of a horizon. Thus, managers shall determine at least one additional period which is referred to a future point of time (e.g., a relevant milestone within a location setup). It is recommended to distribute the periods equally within a horizon. Thirdly, note that the number of periods shall be kept to a necessary minimum, since the effort to gather and operationalize future-oriented data increases with each additional period.

\subsubsection{Planning data}

\section{Location requirements}

(6) Targeted characteristics of objectives $\left(b_{i, t}\right)$

Target values $b_{i, t}$ belong to the location requirement string of the planning data. Within this scope, it can be considered that targets may change over time. Targets are usually determined company-internal by managers.

When determining targets, managers are often capable of doing so in a realistic and precise manner. If this is not the case, two scenarios are common, in which managers are given the following recommendations. A first scenario, where managers envisage a target interval of satisfaction instead of a setting a precise value. Here, it is recommended to set the interval's mean as the target value. This is a practical approximation which does not require methodological depth such as in, e.g., Romero (2001, 2004), or Vitoriano and Romero (1999). A second scenario, where managers are not capable of quantifying any target values. Here, managers are recommended two possible ways. On the one hand, company-external sources may be a helpful reference (e.g., statistics on average property prices). On the other hand, in case of no references, the targets shall be set as strictly as possible to avoid possible decision indifferences due to targets which are set too conveniently (Jones and Tamiz 2010; Tamiz and Jones 1996; Romero 1991).

In doing so, managers shall further question whether their current targets are likely to change over time.

Note that $b_{i, t}$ can be sensitive on location decisions and shall be subject of a sensitivity analysis.

(7) Weight of a positive/negative target deviation regarding objectives $\left(w_{i, t}^{+} / w_{i, t}^{-}\right)$ Weights $w_{i, t}^{+}$and $w_{i, t}^{-}$belong to the location requirement string of the planning data. Within this scope, it can be considered that targets may change over time. Weights are usually determined company-internal by managers. 
When determining weights, managers are often capable of quantifying the relative importance of objectives. If this is not the case (e.g., since implications of weighting strategies are a priori unknown to managers), the following two consecutive steps are recommended following Jones and Tamiz (2010). In a first step, it is sufficient to make a rough estimation of weights or weight all objectives equally. In a second step, different weighting strategies can be incorporated. Managers can determine these weights in two ways. Either intuitively or by using established methods to systematically determine weights for WGP models. For example, the pairwise comparison technique, which is used in, e.g., the AHP (Saaty 1980) or ANP (Saaty 1996), and in combination with GP models (e.g., Özder et al. 2019; Li et al. 2009; Chang et al. 2009; Badri 2001; Gass 1986). For an overview on further weighting techniques see, e.g., Ringuest (1992).

In doing so, managers shall further question whether their current targets are likely to change over time. For setting future-related weights, it is also sufficient to make rough predictions instead to set them ultra-precisely.

Note that $w_{i, t}^{+}$and $w_{i, t}^{-}$can be sensitive on location decisions and shall be subject of a sensitivity analysis.

(8) Minimum/maximum threshold for characteristics of objectives $\left(A_{i, t}^{\min } / A_{i, t}^{\max }\right)$

Thresholds $A_{i, t}^{\min }$ and $A_{i, t}^{\max }$ to the location requirement string of the planning data. Within this scope, it can be considered that thresholds may change over time. Thresholds are usually determined company-external by managers through inquiries with municipal actors.

When determining thresholds, managers can do so in addition to a desired target $\left(b_{i, t}\right)$ for a certain objective. For example, if falling below a minimum required broadband connection (e.g., $A_{i, t}^{\mathrm{min}}=50,000 \mathrm{Mbit} / \mathrm{s}$ ) is not accepted while a certain characteristic (e.g., $b_{i, t}=100,000 \mathrm{Mbit} / \mathrm{s}$ ) is desired. However, it is recommended to managers to handle thresholds carefully and to keep their number to minimum required. Note that the more thresholds considered, the higher the risk for incurring infeasibilities in model computations, and thus an exclusion of possibly relevant solutions for managers become (Jones and Tamiz 2010).

In doing so, managers shall further investigate whether their current thresholds are likely to change over time.

\subsubsection{Location assessment}

(9) Characteristics of location alternatives regarding objectives $\left(a_{i, j}\right)$

Location characteristics $a_{i, j}$ belong to the location assessment string of the planning data. Location characteristics can be gathered company-internal by managers to a limited extent, and thus usually through required inquiries with municipal actors.

Gathering data on location characteristics is usually a huge effort for managers, since several location alternatives must be considered according to multiple objectives. To provide effective support to managers, two consecutive steps 
are recommended. In a first step, managers are referred to free options for selfresearch which can provide helpful first impressions regarding potential locations. First and foremost, online platforms for property-related data (e.g., size, price, and availability of construction plans) and online map services to get relevant data on surroundings of properties (e.g., traffic and social infrastructure) are to be mentioned here. In a second step, an inquire with relevant municipal actors is necessary to get supplementary data on location characteristics (e.g., propertyspecific energy supply, soil contamination, monument preservations, etc.). Here, a helpful assistance to managers is given by location development organizations in terms of bundling relevant data from a city administration's relevant resorts and, if necessary, involving third parties (e.g., investors).

Operationalizing data in a meaningful way is a further vital step by normalizing the gathered data to overcome incomparability, and thus to avoid misleading location decisions. For an overview on normalization techniques see, e.g., Jones and Tamiz (2010), Ginevičius (2008), Tamiz et al. (1998), and Tamiz and Jones (1996).

Note that the choice of a normalization technique can be sensitive on location decisions and shall be subject of a sensitivity analysis.

(10) Investment requirements for location set-up $\left(I C_{j}\right)$

Investment requirements for setting up a location $I C_{j}$ belong to the location assessment string of the planning data. Within this scope, it can include the sum of relevant location-specific financial expenses (e.g., for property purchase, preparation, construction, etc.). Investment requirements for a location set-up can be gathered company-internal by managers to a limited extent, and thus usually through required inquiries with municipal actors.

To determine investment requirements in a systematic way, managers are recommended to use pertinent norms (e.g., the DIN-norm 276 for location set-up projects within Germany). Nevertheless, a close consultation with economic development organizations is inevitable, since they ensure the effective communication to relevant third parties when setting up locations (e.g., a city's building or nature protection authority). Managers shall note that $I C_{j}$ shall be determined in case when the purchase of properties or buildings is intended, respectively. In case when a rent or lease is of interest, $I C_{j}$ can be neglected (i.e., set as zero) and instead an according objective shall be specified.

\subsubsection{Location development}

(11) Company-driven measures: impact on objectives $\left(C E_{i, j, m}\right)$

The impact of company-driven measures on objectives $C E_{i, j, m}$ belongs to the location development string of the planning data. Within this scope, it can be considered that a measure may have an impact on one or more objectives. The impact of company-driven measures can be gathered company-internal by managers to a limited extent, and thus usually through required inquiries with municipal actors. When determining the impact of company-driven measures, first, managers shall examine whether the impact is dependent or independent on location-specific cir- 
cumstances. For each scenario, a suitable operationalization strategy is recommended. The strategies are then illustrated, and relevant implications are deduced for managers. In a scenario of dependency (i.e., when a measure is not realizable in general or to a desired extent in at least one potential location), managers shall conduct a location-specific operationalization of the measure impact. For this, it is helpful to refer to the maximum achievable impact of this measure on an objective at a certain location (strategy 1), whereby a close consultation with municipal actors is inevitable to get this information. In a scenario of independency, managers have a maximum degree of freedom when operationalizing the impact of measures. For this, a good orientation is to refer to the target $\left(b_{i, t}\right)$ which is set for the objective to be influenced by the measure, with $C E_{i, j, m}=b_{i, t}$ (strategy 2). In case that the target is likely to change over time, reference shall be made to the strictest value to ensure target achievement any time when realizing the measure. Given space availability (sqm) as an objective of relevance, a corresponding target is set with $b_{i, t}=50,000 \mathrm{sqm}$ (constant over time) and two alternatives are considered. Location A with 40,000 sqm and location B with 45,000 sqm. Since both locations fall below the target, a company-driven measure is intended for space expansion by managers. Note that the space at both locations is expandable to a limited extent (i.e., by a maximum of $5000 \mathrm{sqm}$ and 10,000 sqm at location A and location $\mathrm{B}$, respectively).

Following strategy (1) for operationalization, the measures' impact is correctly specified in a location-specific way, i.e., with $C E_{i, j, m}=5000 \mathrm{sqm}$ at location A and $C E_{i, j, m}=10,000 \mathrm{sqm}$ at location B. Following strategy (2), the measures' impact is specified as $C E_{i, j, m}=50,000 \mathrm{sqm}$ at both locations, and thus relevant locationspecific circumstances are neglected.

The decision recommendations at the potential location, when following the strategies, would be as follows. Location A; Strategy (1): realize measure with $100 \%$ intensity to expand the property by 5000 to $45,000 \mathrm{sqm}$. It is noted that the manager's target of 50,000 sqm remains unachieved; Strategy (2): realize measure with $20 \%$ intensity to expand the property by 10,000 to $50,000 \mathrm{sqm}$. It is noted that this decision recommendation would result in an exact achievement of the manager's target. However, the measure would not be realizable, as relevant circumstances at location A are neglected. Location B; Strategy (1): realize measure with $50 \%$ to expand the property by 5000 to $50,000 \mathrm{sqm}$. It is noted that the manager's target is exactly achieved; Strategy (2): realize measure with $10 \%$ intensity to expand the property by 5000 to $50,000 \mathrm{sqm}$. It is noted that this decision recommendation would result in an exact achievement of the target.

Given the exemplary findings, managers shall note two main things. For one thing, strategy (1) is to be preferred, as it is beneficial in operationalizing a measure's impact in a realistic way, and thus ensures its realizability in practice. However, the challenge for managers is to gather the necessary data, especially by inquiring with municipal actors. For the other thing, strategy (2) is considered as useful in case when managers do not have this data due to comparatively low data requirements. However, this is contrasted by the risk of deriving decision recommendations which are not necessarily realizable in practice.

(12) Company-driven measures: investment requirements $\left(I D_{j, m, t}\right)$ 
Investment requirements for company-driven measures $I D_{j, m, t}$ belong to the location development string of the planning data. Within this scope, it can include the sum of non-recurring financial expenses (e.g., for the purchase of additional space, upcoming real estate taxes, etc.). Investment requirements for company-driven measures can be gathered company-internal by managers to a limited extent, and thus usually through required inquiries with municipal actors.

When determining the investment requirements, managers often do so roughly in a first step. To make a more accurate and reliable specification it is of vital importance to consult with municipal actors who may further involve third parties, depending on development plans of companies.

Managers shall note two things. First, the final investment requirement of a company-driven measure is dependent on its chosen intensity or how it is dimensioned though computations, respectively. Second, the final investment requirement is charged once (i.e., at realization point of time of the measure).

(13) Company-driven measures: follow-up costs $\left(F C_{j, m, t}\right)$

Follow-up costs for company-driven measures $F C_{j, m, t}$ belong to the location development string of the planning data. Within this scope, it can include the sum of recurring financial expenses (e.g., taxes for additional space that arise regularly). Follow-up costs for company-driven measures can be gathered company-internal by managers to a limited extent, and thus usually through required inquiries with municipal actors.

When determining follow-up costs, managers are referred to the notes with respect to the determination of investment requirements $I D_{j, m, t}$ given above. In addition, managers shall note two aspects. First, in case of an insufficient data situation, a useful approximation is to specify follow-up costs as a certain percentage of the total investment requirements $I D_{j, m, t}$ for a measure's realization. Second, follow-up costs are charged recurrently in future periods when a certain measure is realized.

(14) Municipal measures: impact on objectives $\left(M E_{i, j, s, t}\right)$

The impact of municipal measures on objectives $M E_{i, j, s, t}$ belongs to the location development string of the planning data. Within this scope, it can be considered that a measure may have an impact on one or more objectives. The impact of municipal measures is usually gathered company-external by managers through required inquiries with municipal actors.

To managers it is recommended, to jointly ascertain what impact current and future municipal measures will likely have on characteristics of relevant objectives at the location alternatives of interest and their surroundings. To operationalize the impact of municipal measures, two steps are recommended to managers. Firstly, municipal measures which are already identified for realization at potential locations shall be further specified in terms of time. For this, it is suggested to inform the municipal actors about the planning horizon specified by managers. Then, managers must assign an obtained municipal measure to an already specified planning period which is closest to the measure's planned realization date. Secondly, the impact of municipal measures on characteristics of one or more objectives must be determined by municipal actors 
in a joint discussion with managers. Experiences show that, especially subordinated economic development organizations and municipalities can quantify the impact of measures in a reliable way.

\subsubsection{Other}

Finally, the overall budget $B(15)$ and calculatory interest rate $h(16)$ belong to the planning data. The parameters are usually gathered company-internal by managers.

Note that the latter can be neglected (i.e., set as zero) in case when the discounting of future investments and follow-up costs for company-driven measures are not required.

\section{Validation of the decision support framework based on a real-life application}

\subsection{Aim and case study}

In this section, it is the aim to validate the developed decision support framework based on a real-life case study in regional facility location and development planning. The validation is done quasi ex-post, i.e., the database at the past decision point of time is considered. Note that, within this validation, it is explicitly not intended to make better decisions based on an over-time improved database. An ex-ante validation is not appropriate for an initial validation of the framework due to the long timespan that usually must pass to allow a company to judge on its long-term satisfaction.

Within the quasi ex-post validation, main results which are derived through application of the decision support framework are compared to a company's decisions made in the past. In doing so, three objectives are pursued regarding the developed decision support framework. Firstly, advantages compared to conventional FLP approaches are examined. Secondly, potentials for a practical use in regional facility location and development planning are analyzed. Thirdly, the decision recommendations are analyzed with respect to sensitivity. As a result, the validity of the presented decision support framework for the regional facility location and development planning is depicted.

The case study includes a SME with focus on IT-consulting which is located within the German region Brandenburg. In the past, the company was dissatisfied with its former location, and thus a new location and respectively a rental object situated on it was sought. Within the relocation project, the CEO (i.e., decisionmaker) assessed a handful of potential location alternatives and, additionally, intended measures to develop them in line with his own requirements. Besides, municipal measures for the development of potential locations were considered. 
In the following, the relevant database is created, and computational results are derived by means of the developed decision support framework.

\subsection{Guideline-based data gathering and operationalization}

Using the guideline from Sect. 3.2, decision-relevant master and planning data were gathered and operationalized.

Master data (i.e., indices) are given at first. There are nine decision-relevant objectives $(I=9)$ which serve as a basis for the assessment of six location alternatives $(J=6)$. Moreover, two company-driven measures $(M=2)$ are intended for the development of a suitable location. To be more concrete, measures for an expansion of office space capacities and an installation of a redundant broadband connection are planned. Redundant broadband infrastructure shall prevent possible data losses due to power failures, which may be critical for IT-focused companies. Further, the decision-maker considers two municipal measures for the development of potential locations $(S=2)$. Herein, municipal measures for a renovation of urban rail systems and a construction of a federal highway are intended. In addition, there are some more municipal measures which, however, are not considered as decision-relevant from the decision-maker's point of view. Also, three periods $(T=3)$ are considered, each representing a yearly quarter. The planning horizon covers the time span from the decision up to the envisaged relocation point of time, and thus is quite short compared to common horizons in FLPs.

Planning data (i.e., parameters) are introduced in the following. The decisionmaker's location requirements with respect to decision-relevant objectives are given in Table 2. Note that some specifications are not applicable (-) to certain objectives.

Here, objectives $i=1$ to $i=7$ are quantitative and measurable (e.g., in Euro/sqm, minutes, etc.). In contrast, objectives $i=8$ and $i=9$ are qualitative and their characteristics are difficult to measure. To this end, both qualitative objectives are transformed into a categorical scale by using proper maturity scales (e.g., as in Mettler

Table 2 Planning data: location requirement parameters

\begin{tabular}{|c|c|c|c|c|c|c|c|}
\hline \multicolumn{3}{|c|}{ Objectives } & \multirow{2}{*}{$\begin{array}{l}\text { Targets } \\
b_{i, t}\end{array}$} & \multicolumn{2}{|c|}{ Weights } & \multicolumn{2}{|c|}{ Thresholds } \\
\hline$I=9$ & Description & Unit & & $w_{i, t}^{-}$ & $w_{i, t}^{+}$ & $A_{i, t}^{\min }$ & $A_{i, t}^{\max }$ \\
\hline$i=1$ & Rental price & Euro/sqm & 10 & - & 1 & - & 20 \\
\hline$i=2$ & Redundant broadband connection & Binary & - & 1 & - & 1 & - \\
\hline$i=3$ & Bus transport accessibility & Minutes & - & - & 1 & - & 5 \\
\hline$i=4$ & Railway transport accessibility & Minutes & - & - & 1 & - & 10 \\
\hline$i=5$ & Air transport accessibility & Minutes & - & - & 1 & - & 30 \\
\hline$i=6$ & Travel time from staff residences & Minutes & - & - & 1 & - & 40 \\
\hline$i=7$ & Office space capacity & \# Persons & 12 & 1 & - & 12 & - \\
\hline$i=8$ & Dining infrastructure & Scale $1-4$ & 3 & 0.5 & - & - & - \\
\hline$i=9$ & Wellbeing & Scale $1-4$ & 3 & 0.5 & - & - & - \\
\hline
\end{tabular}


2010). This is illustrated based on the example wellbeing $(i=9)$. For assessment purposes, the decision-maker specifies four dimensions: maintenance condition of a rental object, optical attractiveness, surroundings, and relationship to the rental agent. Based on this, four maturity levels and a corresponding assessment logic are specified. Thus, each maturity level indicates how the wellbeing $(i=9)$ differs between potential location.

For each objective's characteristic, the targets $b_{i, t}$ are set by the decision-maker. He can set precise values for $b_{i, t}$ where necessary. He is aware of different objective types and can specify whether positive and/or negative target deviations shall be considered as unwanted, and thus shall be penalized. To this end, he specifies preferential weights $w_{i, t}^{-}$and $w_{i, t}^{+}$in an intuitive way. The use of established weighting methods is not required. Thus, the decision-maker intuitively considers quantitative objectives as twice as important as qualitative ones. This is formalized by penalizing the unwanted target deviations regarding quantitative and qualitative objectives with the values 1 and 0.5 , respectively. Within each objective type, no further distinction in terms of preferential weighting is made. The interaction between target deviations and preferential weights is explained based on two examples. Firstly, for rental price $(i=1)$, the decision-maker sets the target value $b_{i, t}=10$ Euro/sqm. Since a rental price higher 10 Euro/sqm is considered as unwanted, a positive target deviation is penalized $\left(w_{i, t}^{+}=1\right)$. Accordingly, a rental price lower 10 Euro/sqm is accepted, and thus negative target deviations are not penalized $\left(w_{i, t}^{+}=0\right)$. Secondly, for office space capacity $(i=7)$, the decision-maker sets the target value $b_{i, t}=12$ persons. Correspondingly, $w_{i, t}^{-}=1$ is specified, as negative target deviations are contrary to his requirement. In response to an explicit request, the decision-maker stated that he is fully satisfied with the attainment of each target. This implies that his utility concerning a certain location factor is maximal, and thus each additional unit of acceptance (i.e., the lower/higher the better) does not contribute to an increase of his utility. Therefore, his decision behavior coincides with the satisficing principle of the WGP.

Further, the decision-maker specifies minimum and maximum requirement thresholds $\left(A_{i, t}^{\min } / A_{i, t}^{\max }\right)$ in addition to targets. To the decision-maker's mind, a nonconformity with those is very critical to the company's success, and thus affected locations are disqualified.

The decision-maker assumes that his location requirements remain constant over time what applies to all the parameters given in Table 2 above.

In Table 3, relevant parameters for location assessment are given. These are actual location characteristics $\left(a_{i, j}\right)$ and investment requirements for the set-up of locations $\left(I C_{j}\right)$. Regarding the former, for example, it is noted that location $j=3$ have no redundant broadband connection $(i=2)$. According to the minimum requirement threshold $\left(A_{i, t}^{\min }=1\right)$ specified earlier, $j=3$ would be thus disqualified unless company-driven or municipal measures do not contribute to an enhancement.

Facing the objective's differing units of measurement in location assessment, a percentage normalization according to Jones and Tamiz (2010) is conducted to ensure commensurability, and thus to avoid misleading decision recommendations. Given the case study, percentage normalization is appropriate, since precise target values are set, from which no one is degenerated (i.e., equal zero). For each 
Table 3 Planning data: location assessment parameters

\begin{tabular}{|c|c|c|c|c|c|c|c|c|}
\hline \multicolumn{3}{|c|}{ Objectives } & \multicolumn{6}{|c|}{ Actual location characteristics $\left(a_{i, j}\right)$} \\
\hline$I=9$ & Description & Unit & $j=1$ & $j=2$ & $j=3$ & $j=4$ & $j=5$ & $j=6$ \\
\hline$i=1$ & Rental price & Euro/sqm & 18.5 & 11.5 & 19.5 & 12 & 14 & 15 \\
\hline$i=2$ & $\begin{array}{l}\text { Redundant broadband } \\
\text { connection }\end{array}$ & Binary & 1 & 1 & 0 & 1 & 1 & 1 \\
\hline$i=3$ & $\begin{array}{l}\text { Bus transport acces- } \\
\text { sibility }\end{array}$ & Minutes & 4 & 3 & 5 & 4 & 4 & 2 \\
\hline$i=4$ & $\begin{array}{l}\text { Railway transport acces- } \\
\text { sibility }\end{array}$ & Minutes & 10 & 7 & 5 & 3 & 10 & 8 \\
\hline$i=5$ & $\begin{array}{l}\text { Air transport acces- } \\
\text { sibility }\end{array}$ & Minutes & 29 & 29 & 4 & 18 & 20 & 17 \\
\hline$i=6$ & $\begin{array}{l}\text { Travel time from staff } \\
\text { residences }\end{array}$ & Minutes & 30 & 35 & 30 & 35 & 35 & 40 \\
\hline$i=7$ & Office space capacity & \# Persons & 12 & 6 & 9 & 8 & 12 & 12 \\
\hline$i=8$ & Dining infrastructure & Scale $1-4$ & 3 & 3 & 3 & 3 & 2 & 2 \\
\hline$i=9$ & Wellbeing & Scale $1-4$ & 3 & 4 & 3 & 2 & 1 & 4 \\
\hline \multicolumn{2}{|c|}{ Investment requirement for location set-up $\left(I C_{j}\right)$} & Euro & - & - & - & - & - & - \\
\hline
\end{tabular}

objective, a normalization constant $k_{i}$ is determined by $k_{i}=b_{i, t} / 100$. The percentage of requirement fulfilment is determined by $b_{i, t}^{*}=\frac{b_{i, t}}{k_{i}}$ subsequently. Taking the office space capacity $(i=7)$ as example, $k_{i}$ is determined as follows: $\frac{12}{100}=0.12$. Regarding an actual office space capacity of $a_{i, j}=6$ persons (e.g., at location $j=2$ ) an absolute target deviation of $d_{i, j, t}^{-}=6$ persons is depicted. Finally, the percentage deviation is determined by dividing the absolute deviation by $k_{i}: \frac{6}{0.12}=50$. Concluding, the actual characteristic at $j=2$ deviates by $50 \%$ from the decision-maker's target value $b_{i, t}=12$ persons.

With respect to the investment requirements for the location set-up $\left(I C_{j}\right)$, the decision-maker renounces their specification since an object for rent is of interest.

In the following, relevant parameters for location development are given. This includes the impact of company-driven and municipal measures as well as financial expenses for the former.

In Table 4, the operationalized impacts of company-driven and municipal measures on decision-relevant objectives are given with $C E_{i, j, m}$ and $M E_{i, j, s, t}$, respectively. In this case study, each measure impacts exactly one objective. To operationalize the impact of company-driven measures, the decision-maker follows strategy (2) from the guideline, since there is no necessity to consider location-specific circumstances. Consequently, the impact of measures coincides with the target value for a certain objective which shall be developed $\left(C E_{i, j, m}=b_{i, t}\right)$. For example, the impact of measure expanding office space capacity $(m=1)$ on objective $i=7$ is specified as $C E_{i, j, m}=b_{i, t}=12$ persons. Thus, an actual characteristic of $i=7$ at a location could be further developed up to a maximum capacity 
Table 4 Planning data: location development parameters-impact of measures

\begin{tabular}{|c|c|c|c|c|c|}
\hline \multicolumn{2}{|c|}{ Measures for location development } & \multicolumn{4}{|c|}{ Impact on objectives } \\
\hline \multicolumn{2}{|c|}{ Description } & $i=2$ & $i=4$ & $i=6$ & $i=7$ \\
\hline$M=2$ & Company-driven measures & \multicolumn{4}{|l|}{$C E_{i, j, m}$} \\
\hline$m=1$ & Expanding office space capacity & - & - & - & +12 persons \\
\hline$m=2$ & Establishing redundant broadband connection & +1 & - & - & - \\
\hline$S=2$ & Municipal measures & \multicolumn{4}{|l|}{$M E_{i, j, s, t}$} \\
\hline$s=1$ & Renovation of urban rail systems & - & $+9 \min$ & - & - \\
\hline$s=2$ & Construction of federal highways & - & - & $-5 \min$ & - \\
\hline
\end{tabular}

of 12 persons (assuming a 100\% measure intensity). Since the actual characteristics of $i=7$ differ amongst potential locations, the importance of an accurate measure dimensioning becomes clear when trying to achieve the desired capacity $\left(b_{i, t}=12\right.$ persons $)$.

From the municipal perspective, a measure for the renovation of urban rail systems $(s=1)$ is planned at location $j=6$ in future $\left(t_{1}\right)$. However, from the decision-maker's point of view, this development is a serious worsening of the railway transport accessibility $(i=4)$ by approximately $9 \min \left(M E_{i, j, s, t}=9 \mathrm{~min}\right)$. Moreover, a municipal measure for construction of federal highways $(s=2)$ is planned at locations $j=3, j=4$, and $j=6$ in future $\left(t_{2}\right)$. This development would lead to a shortening of the travel time from staff residences $(i=6)$ by approximately $5 \min \left(M E_{i, j, s, t}=-5 \mathrm{~min}\right)$, and thus would have a positive impact.

In Table 5, financial expenses are given for company-driven measures which refer to the investment requirements $I D_{j, m, t}$ and associated follow-up costs $F C_{j, m, t}$.

Here, the investment refers to financial expenses for reconstruction works on rental objects $(m=1)$ and extension works for broadband infrastructure $(m=2)$. For both measures, the decision-maker estimates follow-up costs at $10 \%$ of the corresponding investment requirements. Regarding measure $m=2$, investments and follow-up costs are considered just at location $j=3$, because it is the only location where a development of redundant broadband connection $(i=2)$ is required.

Table 5 Planning data: location development parameters-financial expenses for company-driven measures

\begin{tabular}{|c|c|c|c|c|c|c|c|c|}
\hline \multicolumn{2}{|c|}{ Company-driven measures } & \multicolumn{7}{|c|}{ Financial expenses [Euro] } \\
\hline$M=2$ & Description & & $j=1$ & $j=2$ & $j=3$ & $j=4$ & $j=5$ & $j=6$ \\
\hline \multirow[t]{2}{*}{$m=1$} & \multirow[t]{2}{*}{ Expanding office space capacity } & $I D_{j, m, t}$ & 20,000 & 20,000 & 85,000 & 130,000 & 60,000 & 40,000 \\
\hline & & $F C_{j, m, t}$ & 2000 & 2000 & 8500 & 13,000 & 6000 & 4000 \\
\hline \multirow[t]{2}{*}{$m=2$} & \multirow{2}{*}{$\begin{array}{l}\text { Establishing redundant broad- } \\
\text { band connection }\end{array}$} & $I D_{j, m, t}$ & - & - & 5000 & - & - & - \\
\hline & & $F C_{j, m, t}$ & - & - & 500 & - & - & - \\
\hline
\end{tabular}


Finally, the decision-maker specifies the outstanding planning data. Herein, the parameter regarding the overall budget is specified as $B=100,000$ Euro. Further, he renounces a parameter specification with respect to the interest rate $h$ due to the quite short planning horizon. By setting $h=0$, the discount rate is equal one for each period, and thus no discounting of future financial expenses is conducted.

\subsection{Planning model application}

Based on gathered and operationalized planning information, the mathematical planning model from Sect. 3.1 is applied. In doing so, the planning information and model are implemented into a decision support software. Subsequently, results are presented which are obtained through a model computation.

The implementation of operationalized planning information and developed planning model is based on the use of optimization software. The model formulation was implemented using AIMMS and solved with the GUROBI 9.0 solver on a standard computer having a $2.7 \mathrm{GHZ}$ CPU and 16 GB RAM.

To obtain results, two different planning settings were considered. The first setting is a RFLDP setting in which both company-driven and municipal development measures are considered over time. The RFLDP setting corresponds to that of the case study. The second setting is a conventional planning setting in which any development measures are neglected. Here, actual characteristics of decision-relevant objectives at potential locations are thus considered as main decision basis. The conventional setting is obtained by reducing the extent of the introduced planning model according to those considered within existing FLP models.

The problem instances of both settings are roughly of the same size. The RFLDP setting comprises a total of 1793 constraints, 1113 variables (six of them integer), and 3715 non-zeros. Here, the computer takes $0.03 \mathrm{~s}$ to determine an optimal location configuration. For both settings, the results are given in Table 6.

The model's decision recommendations address the location selection and development. There are three main findings. Firstly, the results between both planning settings differ structurally which can be seen in different location recommendations. Secondly, in the RFLDP setting, in addition to selecting location $j=2$, its targetoriented development is recommended. Here, the allocation of measure expanding office space capacity $(m=1)$ with $50 \%$ intensity is proposed in $t_{0}$ which leads to a fulfillment of the decision-maker's target and minimum requirement $\left(b_{i, t}=A_{i, t}^{\min }=\right.$ 12 persons). When neglecting this company-driven development, the actual characteristic at location $j=2$ with $a_{i, j}=6$ persons regarding office space capacity $(i=7)$

Table 6 Computational results: decisions in distinct planning settings

\begin{tabular}{llllll}
\hline Planning setting & Location & \multicolumn{4}{l}{ Allocation and dimensioning of company-driven measures } \\
\cline { 3 - 6 } & & \multicolumn{2}{l}{ Description } & Intensity & Period \\
\hline (1) RFLDP & $j=2$ & $m=1$ & Expanding office space capacity & $50 \%$ & $t_{0}$ \\
(2) Conventional & $j=6$ & - & - & - & - \\
\hline
\end{tabular}


is insufficient. Accordingly, location $j=2$ is disqualified in the conventional setting. Thirdly, in the conventional setting, the choice of location $j=6$ is proposed instead. Here, a municipal measure for renovation of urban rail systems $(s=1)$ is intended in the future which is a serious worsening of the railway transport accessibility $(i=4)$, as the maximum acceptable threshold is exceeded $\left(A_{i, t}^{\max }=10 \mathrm{~min}\right)$. If the location development is neglected, the model does not anticipate that the manager's requirements will not be met in the future. Against the background, location $i=6$ should be discarded as a possible alternative.

\subsection{Sensitivity analysis}

The results are investigated with respect to sensitivity. Following the guideline, a sensitivity analysis is conducted on parameters respecting targets $\left(b_{i, t}\right)$, preferential weights $\left(w_{i, t}^{+} / w_{i, t}^{-}\right)$, and normalization constants $\left(k_{i}\right)$. The parameters are structurally varied within different scenarios (see Table 8 in the Appendix). For each parameter, the corresponding scenarios and related variations are outlined below.

For the targets, three scenarios are considered. In the basic scenario (TS-0), the targets $b_{i, t}$ are equal to the values of the case study. In the strict scenario (TS-1), all targets are set strictly, and thus are much harder to achieve than in TS-0. In the convenient scenario (TS-2), the targets are set conveniently, and thus are much easier to achieve than in TS- 0 . Note when varying $b_{i, t}$, a corresponding company-driven measure's impact is also adjusted as required by the operationalization strategy (2).

For the weights, three scenarios are considered. In the basic scenario (WS-0), the weights $w_{i, t}^{+}$and $w_{i, t}^{-}$are equal to the values of the case study. In the qualitative weighting scenario (WS-1), all qualitative objectives are considered twice as important as quantitative ones. In the equality scenario (WS-2), all objectives are weighted equally.

For the normalization constants, five scenarios are considered. In the basic scenario (NS-0), the constants $k_{i}$ are normalized by percentage as in the case study. In the euclidean scenario (NS-1), the summation scenario (NS-2), and the zero-one scenario (NS-3) $k_{i}$ are normalized according to the respective normalization technique. Finally, a scenario is considered in which normalization is neglected (NS-4). With respect to NS-3, note that a specification of $k_{i}$ is not required, since no corresponding targets were formulated by the decision-maker. For a detailed explanation of the normalization techniques, reference is made to, e.g., Jones and Tamiz (2010).

The scenarios are analyzed in a ceteris-paribus way, starting from the basic scenarios. This allows to evaluate the effect of one scenario change at a time. Therefore, 8 additional problem instances are derived, each of which was planned according to the RFLDP and the conventional planning setting. Each scenario was solved within $3 \mathrm{~s}$.

In Table 7, the results of the scenario analysis are given. The initial case study results are based on the respective basis scenarios (TS-0/WS-0/NS-0). Four main findings are noted. First, although the structural results are similar in most scenarios, the corresponding objective function values (OFV) largely differ. This is due to strongly differing target deviations depending on the parameter configurations. Second, independent from the scenario configuration, the obtained results in the RFLDP and conventional setting are fundamentally different. There is no scenario in which 


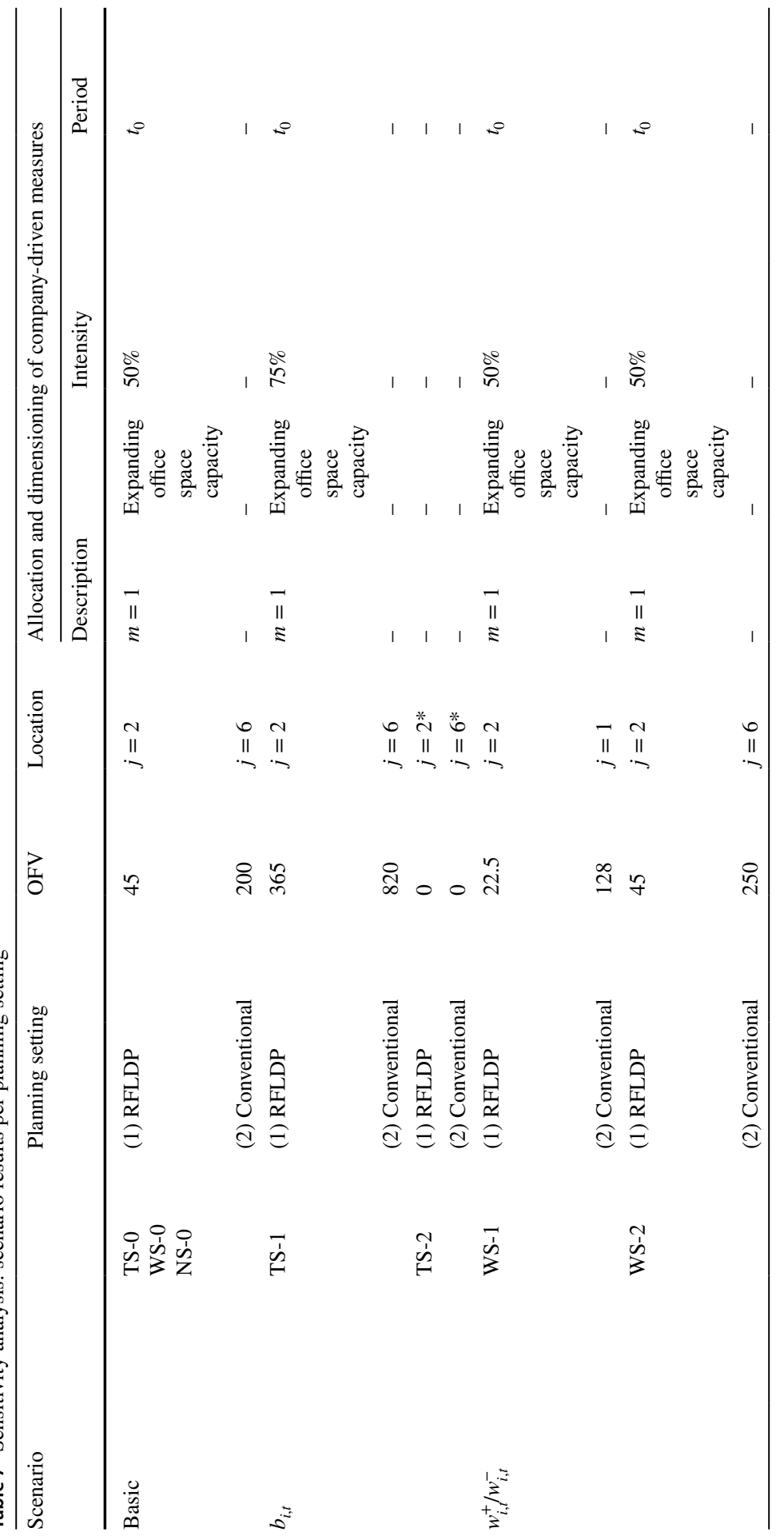




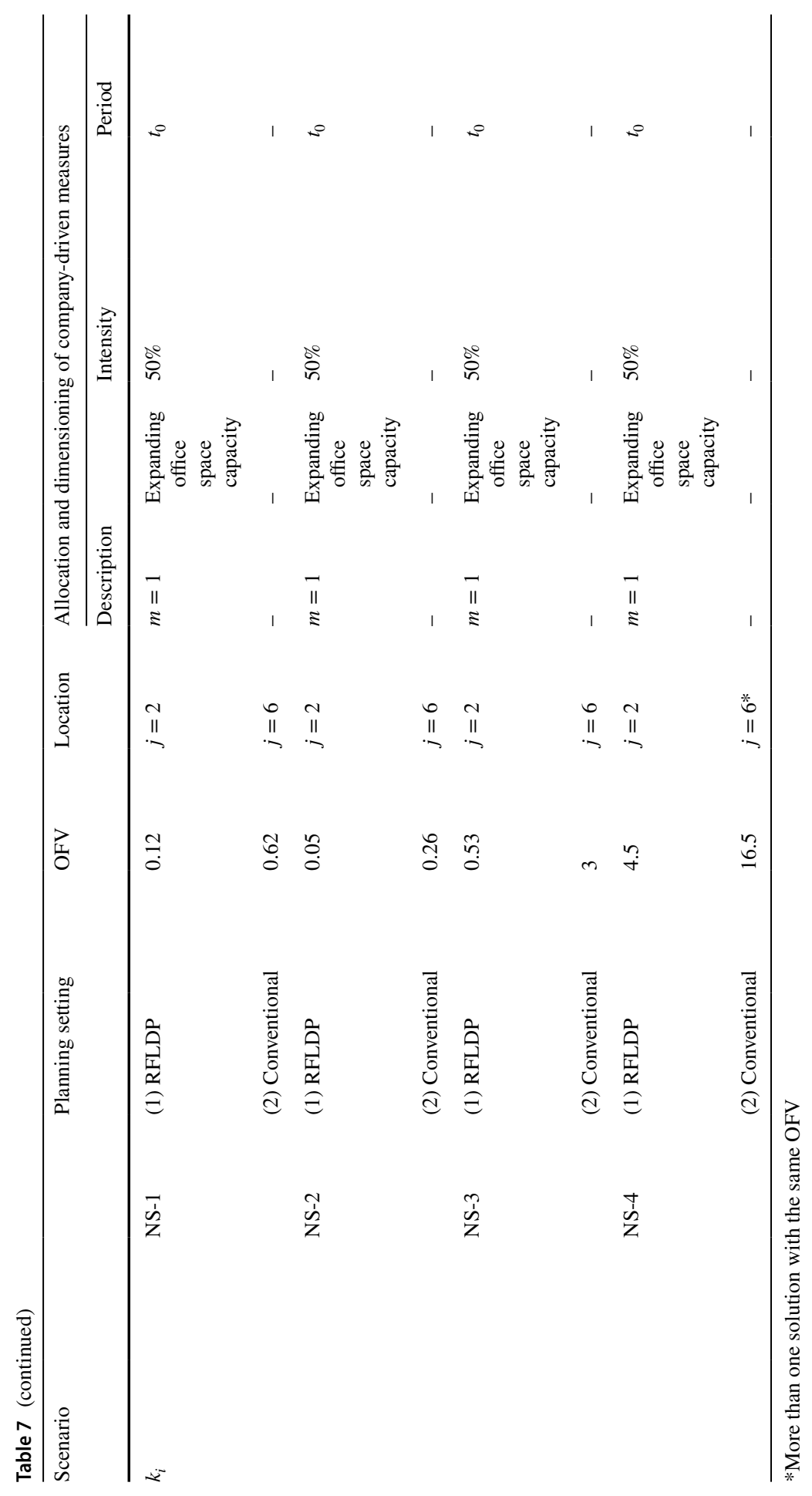


the location selection is the same for both planning approaches. Third, the results show that the structure of the solution is most sensitive to the targets $b_{i, t}$. In the RFLDP and conventional setting, a convenient specification of $b_{i, t}$ (TS-2) results in the locations (excepting $j=3$ ) being satisficing to an equal extent $(\mathrm{OFV}=0)$. Thus, there are indifferences between those locations. Fourth, the solution structure is less sensitive to the preferential weights $w_{i, t}^{+} / w_{i, t}^{-}$and the normalization constants $k_{i}$. In the RFLDP setting, there are no differences in the structure of results along the considered variations of both parameter types. However, there are differing results in the conventional setting. On the one hand, location $j=1$ is preferred instead of initially $j=6$ when qualitative objectives are considered as twice as important quantitative ones (WS-1). On the other hand, when neglecting normalization (NS-4), there are indifferences between locations $j=5$ and $j=6$, as both are satisficing to an equal extent (both with OFV=16.5).

In summary, it is noted that location decisions differ structurally depending on the chosen planning setting. Location decisions recommended in the RFLDP setting are more robust than those derived within the conventional setting, since the decision remains the same across the scenarios. Different parameter variations alone do not necessarily result in structural changes within the use of one planning setting. Nevertheless, a few outliers are observed for parameter variations, especially in the conventional setting.

Note that the conclusions are based on the given data within the investigated case study and deviating implications can be likely observed for other RFLDP case studies. Thus, managers shall always question to what extent alternative parameter specifications may affect the location decision.

\subsection{Validity and advantages}

Results obtained with the practical application of the decision support framework are examined below.

To this end, the practical validity of model-based decision recommendations, and thus the planning model's advantages compared to conventional FLP models are pointed out. In addition, benefits of the complementary guideline are discussed from a practical point of view.

For validity examination, the model-based decision recommendations in Sect. 4.3 are compared with two distinct real-life decisions within the case study. The first decision is the company's location decision that was made in the past. The decision-maker decided in favor of location $j=2$. In addition, a development at $j=2$ to increase the office space capacity $(i=7)$ up to a capacity of twelve persons was arranged. The decisions were made under consideration of intended municipal developments. Further, the real-life decisions in this regional location and development planning were unambiguous according to the decision-maker. Meanwhile, the company is settled at $j=2$ since around seven years and the decision-maker is still fully satisfied with his decisions. 
The second decision is an alternative which was considered in the first place by the decision-maker. Initially location $j=6$ was preferred based on information on the status quo and without knowledge on municipal measures. After learning about a planned municipal measure to renovate urban rail systems $(s=1)$ at location $j=6$, the decision-maker revised his preference. The measure led to a permanent closure of railroad crossings, and thus to a worsening regarding objective railway transport accessibility $(i=4)$. As a result, the decision maker decided for $j=2$.

Through the quasi ex-post validation of the results obtained with the practical application of the decision support framework it is noted that, on the one hand, the assumptions and information of the real-life case study coincide with the RFLDP planning setting and, on the other hand, those of the alternative decision coincides with the conventional setting.

Three main findings are derived based on the results. First, the practical validity of the obtained decision recommendations by the introduced planning model is proved, since the model-based decision recommendations in the RFLDP planning setting coincide with the real-life decisions that were made based on the decisionmaker's heuristic gut feeling. Thus, the planning model provides a valid methodical framework for RFLDPs in practice.

Second, the planning model's superiority is demonstrated over existing FLP models. The computational results for the conventional planning setting show that these models would have resulted in long-term unfavorable decision recommendations. In contrast, the developed planning model provides other and structurally favorable location decisions, because location developments are anticipated.

Third, the guideline's major practical benefit is a considerable contribution to a long-term effective decision-making of companies by bridging information gaps in an early planning phase. On the one hand, by providing managers an objective and transparent way to use the planning model. On the other hand, by fostering a structured communication process between the location-seeking company and relevant municipal actors.

Overall, it is successfully demonstrated that the developed decision support framework is an appropriate methodological backbone for real-life RFLDPs. The ex-post validation findings achieve trust in the proposed methodology and indicate potentials for accompanying future planning of companies. This is strengthened by a thoroughly positive feedback from the decision-maker. According to his statements, the proposed methodology's major practical value is seen in getting rid of the widespread heuristic gut feeling when deciding on locations and in a transparent decision-making process. The decision-maker would have been delighted to receive such a methodological and effective support at the decision point of time and, additionally, he would not hesitate to make use of the developed decision support framework to make possible location decisions in future. 


\section{Managerial implications}

In this section, managerial implications that derive from the research on the RFLDP are outlined. Hereby, main findings derived from the practical application in a reallife case study as well as the potentials when considering an over-time systematic measure planning for location development are discussed. The managerial implications are fourfold.

Firstly, an anticipation of locational dynamics is vital in early planning phases. Especially, location developments over time are a decisive factor for a company's location selection. Thus, a neglect of both company-driven and municipal development measures may result in long-term unfavorable decisions, as a location which is considered as most suitable today does not necessarily pose ideal conditions in future. Unfavorable location conditions may consequently have a negative effect on a company's long-term competitiveness, and thus success. The developed RFLDP decision support framework allows a systematic consideration of locational dynamics and provides helpful means for companies.

Secondly, decision-making in regional location and development planning requires a reliable database. It is obvious that most decision-relevant data must be acquired company-external. Herein, data acquisition usually goes hand in hand with inquiries with municipal actors which are responsible for a company's area of interest. This refers to both, current and future-oriented data. The guideline does not only show where and how certain data is to be effectively gathered from, but also provides instructions on how data shall be operationalized in a meaningful way. Although the mathematical planning model proves to be valid, it would not be applicable meaningfully by managers without the complementary guideline. Nevertheless, the effort for gathering and operationalizing data is not significantly higher than it has been so far. Therefore, the consideration of locational dynamics requires a slight extra effort but leads to significantly more effective location decisions in the long-term.

Thirdly, a sensitivity analysis should be considered as a vital part of decisionmaking. For the case study, the sensitivity of results is exemplary demonstrated with respect to selected data on target values, preferential weights, and normalization constants. It is shown that different parameter variations alone do not result in structurally other location decisions. Rather, the choice of planning setting is decisive. The location decisions in the RFLDP setting are more robust than those in the conventional setting. Although there are no discrepancies in decisions in the RFLDP setting, outliers in the conventional setting indicate that there could be structural decision deviations within the former as well. For that reason, to make decisions more robust, parameters should be subject to a structural variation.

An examination of different target levels is recommended. Nevertheless, targets should be set as realistic as possible with a tendency to strictness. Conveniently set targets may lead to indifferences in the decision-making. 
The determination of ultra-precise preferential weights is not necessary. Instead, their rough estimation or an equal weighting strategy is sufficient in a first step. If weights are used by managers in a second step, it is worth to investigate the implications of different weighting strategies.

A normalization technique's suitability strongly depends on the given data. Herein, the degree of incomparability amongst objectives is a relevant indicator. The higher it is, the more likely results will differentiate between techniques. Within the case study, the degree is quite low, and thus locations decisions are mostly independent of normalization. It is recommended to always make use of more than one normalization technique and to examine effects on the results.

Fourthly, it is shown that a complex methodological framework is meaningfully applicable in practice. The required solution time of just a few seconds is quite negligible within a company's strategic RFLDP, and thus highly acceptable. This allows for an easy comparison of location configurations across a multitude of planning scenarios, so that an ultra-precise gathering of data is not necessarily required. Instead, planning uncertainties may be considered, e.g., by means of a proper scenario analysis. Finally, the focus should be laid on a structural analysis of model-based decision recommendations and less on the analysis of objective function values.

The contribution provides a research-related extension of existing FLP approaches as well as a high degree of practical applicability which can underpin strategic decisions of companies in terms of, both method and content.

\section{Summary and outlook}

The aim of this paper is to introduce a comprehensive decision support framework for the Regional Facility Location and Development planning Problem (RFLDP). The strength of the developed framework is demonstrated based on a case study from reality. In doing so, its practicability and major advantages in terms of making long-term favorable location decisions is shown compared to existing Facility Location Problem (FLP) approaches.

To achieve this aim, in Sect. 2, the state-of-the-art regarding location decisionmaking is described from a practical and literature point of view. It is shown that no suitable FLP approach exists that comprehensively fulfills the main requirements within the RFLDP. Especially, a systematic location development has been neglected so far, and thus there is the need to develop an appropriate decision support for companies. In Sect. 3, a comprehensive decision support framework is introduced for the RFLDP. Herein, possibilities for a systematic operationalization of location developments are provided for the first time. The decision support framework is based on two interplaying components. The first component is a mathematical planning model, which is based on an established Weighted Goal Programming formulation and is adapted to this new application. The second component is a complementary 
guideline, which ensures an effective application of the planning model in practice and indicates the relevant municipal actors in the RFLDP. The developed decision support framework is applied to a real-life case study to demonstrate its strength for practical applications in Sect. 4. Its major advantages are highlighted compared to conventional FLP approaches. Further, the obtained results are examined regarding sensitivity. The validity of the developed decision support framework is successfully proved and the potentials for accompanying the future-oriented planning of companies for the RFLDP are indicated. Based on the findings, managerial implications are derived in Sect. 5.

To sum up, the paper introduces a proper decision support framework for the RFLDP. It clearly goes beyond existing FLP approaches, as it provides an integrated location selection and development.

For future research, the following three directions are considered meaningful. Firstly, the decision support framework could be further developed towards a more realistic approximation of RFLDPs by a consideration of possible nonlinearities. Nonlinearities may possibly appear in economies of scale in the dimensioning of company-driven measures as well as in interdependencies between company-driven and municipal location development measures, leading to non-additive utility correlations when combining certain measures with each other.

Secondly, the decision support framework is currently based on the assumption of deterministic data and could be further developed to adequately cope with possible uncertainties. From the point of view of location-seeking companies, the realizations of municipal location development measures over time are particularly subject to uncertainties. Here, companies usually do not have decision-making authority on municipal measures. Thus, a risk-averse attitude of decision-makers could be incorporated as it is common in strategic planning (Scholl 2001). As a result, robust optimization approaches appear promising to consider uncertainty within the RFLDP.

Thirdly, the potentials of the decision support framework for practical application by municipal actors could be investigated. Especially, the results obtained using the proposed methodology may be of major importance for economic development organizations. Based on the results, they could be able to initiate communication processes with location-seeking companies early on and in a purposeful way. As economic development organizations seek to support municipalities, there is a need to examine the extent to which the decision support framework needs to be further developed to meet the requirements of a municipal planning.

\section{Appendix}

See Table 8. 


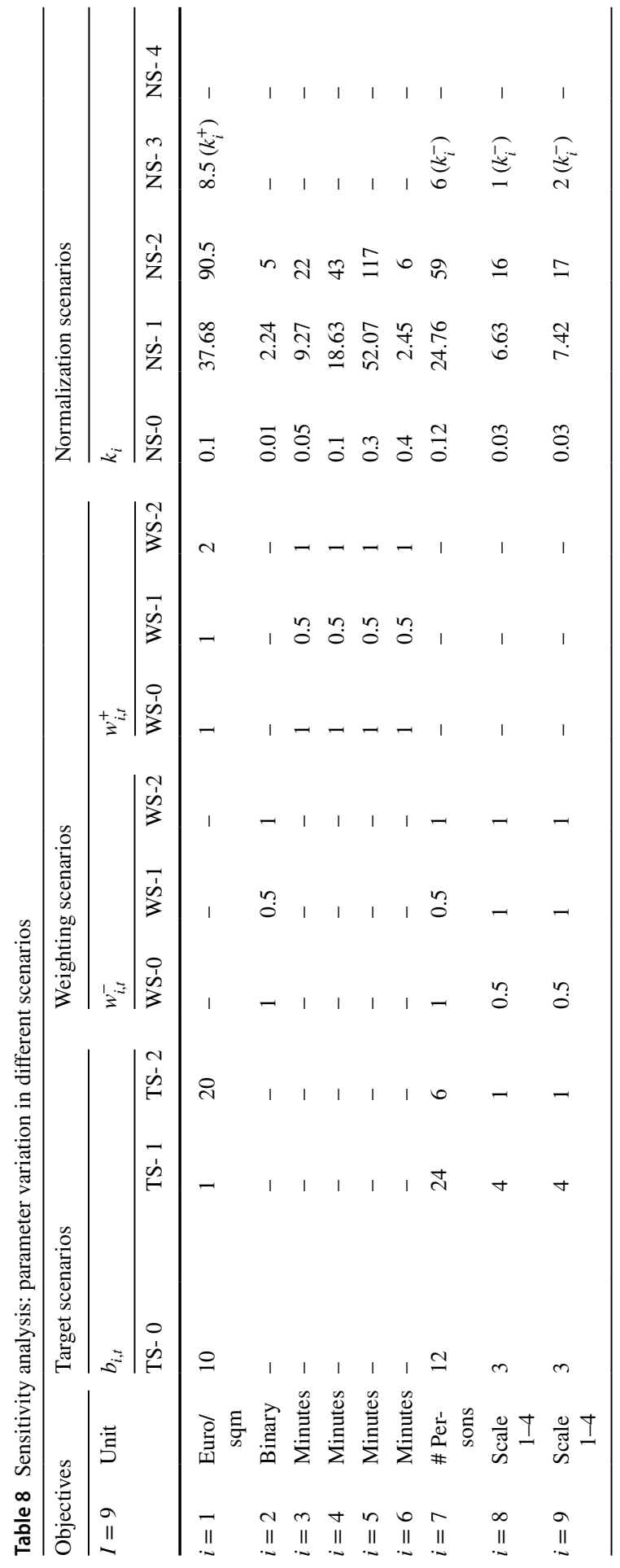


Acknowledgements This work was part of the research project MetroPlant, which was founded by the German Research Foundation under the grant numbers SP 491/8-1 and NY 4/60-1. The authors would like to thank for the support.

Funding Open Access funding enabled and organized by Projekt DEAL.

Open Access This article is licensed under a Creative Commons Attribution 4.0 International License, which permits use, sharing, adaptation, distribution and reproduction in any medium or format, as long as you give appropriate credit to the original author(s) and the source, provide a link to the Creative Commons licence, and indicate if changes were made. The images or other third party material in this article are included in the article's Creative Commons licence, unless indicated otherwise in a credit line to the material. If material is not included in the article's Creative Commons licence and your intended use is not permitted by statutory regulation or exceeds the permitted use, you will need to obtain permission directly from the copyright holder. To view a copy of this licence, visit http://creativecommons.org/licen ses/by/4.0/.

\section{References}

Abdelaziz FB (2007) Multiple objective programming and goal programming: new trends and applications. Eur J Oper Res 177:1520-1522. https://doi.org/10.1016/j.ejor.2005.12.023

Aouni B, Kettani O (2001) Goal programming model: a glorious history and a promising future. Eur J Oper Res 133:225-231. https://doi.org/10.1016/S0377-2217(00)00294-0

Arabani B, Farahani A, Zanjirani R (2012) Facility location dynamics: an overview of classifications and applications. Comp Ind Eng 62:408-420. https://doi.org/10.1016/j.cie.2011.09.018

Badri MA (2001) A combined AHP-GP model for quality control systems. Int J Prod Econ 72:27-40. https://doi.org/10.1016/S0925-5273(00)00077-3

Badri MA, Mortagy AK, Alsayed CA (1998) A multi-objective model for locating fire stations. Eur J Oper Res 110:243-260. https://doi.org/10.1016/S0377-2217(97)00247-6

Barichard V, Gandibleux X, T'Kindt V (eds) (2009) Multiobjective programming and goal programming: theoretical results and practical applications. Springer, Berlin

Caballero R, Gómez T, Ruiz F (2009) Goal programming: realistic targets for the near future. J MultiCrit Decis Anal 16:79-110. https://doi.org/10.1002/mcda.442

Chang Y-H, Wey W-M, Tseng H-Y (2009) Using ANP priorities with goal programming for revitalization strategies in historic transport: a case study of the Alishan Forest Railway. Expert Syst Appl 36:8682-8690. https://doi.org/10.1016/j.eswa.2008.10.024

Charnes A, Cooper WW (1961) Management models and industrial applications of linear programming. Wiley, New York

Charnes A, Cooper WW, Ferguson RO (1955) Optimal estimation of executive compensation by linear programming. Manag Sci 1:138-151. https://doi.org/10.1287/mnsc.1.2.138

Cohon JL (1978) Multiobjective programming and planning. Academic Press, New York

Coll-Martínez E, Arauzo-Carod J-M (2017) Creative milieu and firm location: an empirical appraisal. Environ Plan A 49:1613-1641. https://doi.org/10.1177/0308518X17702646

Current J, Min H, Schilling D (1990) Multiobjective analysis of facility location decisions. Eur J Oper Res 49:295-307. https://doi.org/10.1016/0377-2217(90)90401-V

Dias J, Captivo ME, Climaco J (2008) A memetic algorithm for multi-objective dynamic location problems. J Global Optim 42:221-253. https://doi.org/10.1007/s10898-007-9239-9

Duboz M-L, Kroichvili N, Le Gallo J (2016) Do foreign investors' location determinants in service functions differ according to sectors? An empirical analysis of EU for 1997-2011. Int Reg Sci Rev 39:417-456. https://doi.org/10.1177/0160017615603196

Ehrgott M (2005) Multicriteria optimization, 2nd. Springer, Berlin

Farahani RZ, SteadiSeifi M, Asgari N (2010) Multiple criteria facility location problems: a survey. Appl Math Model 34:1689-1709. https://doi.org/10.1016/j.apm.2009.10.005

Gass SI (1986) A process for determining priorities and weights for large-scale linear goal programmes. J Oper Res Soc 37:779-785. https://doi.org/10.1057/jors.1986.138 
Ginevičius R (2008) Normalization of quantities of various dimensions. J Bus Econ Manag 9:79-86. https://doi.org/10.3846/1611-1699.2008.9.79-86

Hämäläinen RP (2004) Reversing the perspective on the applications of decision analysis. Decis Anal 1:26-31. https://doi.org/10.1287/1030.0012

Hekmatfar M, SteadieSeifi M (2009) Multi-criteria location problem. In: Farahani RZ, Hekmatfar M (eds) Facility location: contributions to management science. Physica, Heidelberg, pp 373-393. https://doi.org/10.1007/978-3-7908-2151-2_16

Hwang C-L, Masud AS (1979) Multiple objective decision making-methods and applications: a state-of-the-art-survey. Springer, Berlin

Hwang C-L, Yoon K (1981) Methods for multiple attribute decision making. Springer, Berlin

Ignizio JP (1976) Goal programming and extensions. Lexington Books, Lexington

Ignizio JP, Romero C (2003) Goal programming. In: Bidgoli H (ed) Encyclopedia of information systems, 2nd edn. Academic Press, San Diego, pp 489-500

Ijiry Y (1965) Management goals and accounting for control. North-Holland, Amsterdam

Jones D, Tamiz M (2010) Practical goal programming. Springer, New York

Kanoun I, Chabchoub H, Aouni B (2010) Goal programming model for fire and emergency service facilities site selection. Infor 48:143-153. https://doi.org/10.3138/infor.48.3.143

Karatas M (2017) A multi-objective facility location problem in the presence of variable gradual coverage performance and cooperative cover. Eur J of Oper Res 262:1040-1051. https://doi.org/10. 1016/j.ejor.2017.04.001

Kik D, Krause M, Wichmann M, Spengler T, Nyhuis P (2018a) Betriebliche Standortplanung und -entwicklung in Metropolregionen: Einblicke in die unternehmens- und kommunenseitige Beeinflussbarkeit qualitativer und quantitativer regionaler Standortfaktoren. ZWF 113:503-507. https://doi.org/10.3139/104.111949

Kik D, Wichmann MG, Krause M, Nyhuis P, Spengler TS (2018b) Multikriterielle Entscheidungsunterstützung in der regionalen Standortplanung und -entwicklung. Or News 64:6-11

Kınay ÖB, Saldanha-da-Gama F, Kara BY (2019) On multi-criteria chance-constrained capacitated single-source discrete facility location problems. Omega 83:107-122. https://doi.org/10.1016/j.omega. 2018.02.007

Laporte G, Nickel S, Saldana da Gama F (eds) (2015) Location science. Springer, Berlin

Lee SM (1972) Goal programming for decision analysis. Auerbach, Philadelphia

Li X, Beullens P, Jones D, Tamiz M (2009) An integrated queuing and multi-objective bed allocation model with application to a hospital in China. J Oper Res Soc 60:330-338. https://doi.org/10.1057/ palgrave.jors. 2602565

MacCarthy BL, Atthirawong W (2003) Factors affecting location decisions in international operations: a Delphi study. Int J Oper Prod 23:794-818. https://doi.org/10.1108/01443570310481568

Malczewski J (2010) Multiple criteria decision analysis and geographic information systems. In: Ehrgott M, Figueira JR, Greco S (eds) Trends in multiple criteria decision analysis. Springer, Boston, pp 369-395

Malczewski J, Ogryczak W (1995) The multiple criteria location problem: 1. A generalized network model and the set of efficient solutions. Environ Plan A 27:1931-1960. https://doi.org/10.1068/ a271931

Malczewski J, Ogryczak W (1996) The multiple criteria location problem: 2. Preference-based techniques and interactive decision support. Environ Plan A 28:69-98. https://doi.org/10.1068/a280069

Malczewski J, Rinner C (2015) Multicriteria decision analysis in geographic information science. In: Balram S, Dragicevic S (eds) Advances in geographic information science. Springer, New York, pp $1-331$

Marttunen M, Lienert J, Belton V (2017) Structuring problems for multi-criteria decision analysis in practice: a literature review of method combinations. Eur J Oper Res 263:1-17. https://doi.org/10. 1016/j.ejor.2017.04.041

Melachrinoudis E, Min H (2000) The dynamic relocation and phase-out of a hybrid, two-echelon plant/ warehousing facility: a multiple objective approach. Eur J Oper Res 123:1-15. https://doi.org/10. 1016/S0377-2217(99)00166-6

Mettler T (2010) Supply chain management im Krankenhaus: konstruktion und evaluation eines konfigurierbaren reifegradmodells zur zielgerichteten Gestaltung. Dissertation, Universität St. Gallen

Mikels JA, Maglio SJ, Reed AE, Kaplowitz LJ (2011) Should I go with my gut? Investigating the benefits of emotion-focused decision making. Emotion 11:743-753. https://doi.org/10.1037/a0023986 
Min H, Melachrinoudis E (1996) Dynamic location and entry mode selection of multinational manufacturing facilities under uncertainty: a chance-constrained Goal Programming approach. Int Trans Oper Res 3:65-76. https://doi.org/10.1111/j.1475-3995.1996.tb00036.x

Mirrazavi SK, Jones DF, Tamiz M (2001) A comparison of genetic and conventional methods for the solution of integer goal programmes. Eur J Oper Res 132:594-602. https://doi.org/10.1016/S03772217(01)00123-0

Nickel S, Puerto J, Rodríguez-Chía AM (2005) MCDM location problems. In: Figueira J, Greco S, Ehrgott M (eds) Multiple criteria decision analysis: state of the art surveys, 2nd. Springer, New York, pp 761-787

Owen SH, Daskin MS (1998) Strategic facility location: a review. Eur J Oper Res 111:423-447. https:// doi.org/10.1016/S0377-2217(98)00186-6

Özder E, Özcan E, Eren T (2019) Staff task-based shift scheduling solution with an ANP and goal programming method in a natural gas combined cycle power plant. Mathematics 7:1-26. https://doi. org/10.3390/math7020192

Pati RK, Vrat P, Kumar P (2008) A Goal Programming model for paper recycling system. Omega 36:405-417. https://doi.org/10.1016/j.omega.2006.04.014

Płaziak M, Szymańska AI (2014) Importance of personal factor in decisions on locating enterprises. Procedia Soc Behav Sci 110:373-380. https://doi.org/10.1016/j.sbspro.2013.12.881

ReVelle C, Cohon JL, Shobrys D (1981) Multiple objectives in facility location: a review. In: Morse JN (ed) Organizations: Multiple Agents with Multiple Criteria. Springer, Berlin, pp 320-337. https:// doi.org/10.1007/978-3-642-45527-8_28

Richter L (2017) Betriebliche Standortplanung auf regionaler Entscheidungsebene. Dissertation, Gottfried Wilhelm Leibniz Universität Hannover

Ringuest JL (1992) Multiobjective optimization: behavioral and computational considerations. Kluwer, Boston

Romero C (1991) Handbook of critical issues in goal programming. Pergamon, Ann Arbor

Romero C (2001) Extended lexicographic goal programming: a unifying approach. Omega 29:63-71. https://doi.org/10.1016/S0305-0483(00)00026-8

Romero C (2004) A general structure of achievement function for a Goal Programming model. Eur J Oper Res 153:675-686. https://doi.org/10.1016/S0377-2217(02)00793-2

Saaty T (1980) The analytic hierarchy process: planning, priority setting, ressource allocation. RWS, State College

Saaty T (1996) The analytic network process. RWS, Pittsburgh

San Cristobal JR (2012) A goal programming model for the optimal mix and location of renewable energy plants in the north of Spain. Renew Sustain Energy Rev 16:4461-4464. https://doi.org/10. 1016/j.rser.2012.04.039

Scholl A (2001) Robuste Planung Und Optimierung: Grundlagen-Konzepte Und Methoden-Experimentelle Untersuchungen. Physica, Heidelberg

Simon HA (1957) Models of man: social and rational: mathematical essays on rational human behavior in a social setting. Wiley, New York

Stewart TJ (1992) A critical survey on the status of multiple criteria decision making: theory and practice. Omega 20:569-586. https://doi.org/10.1016/0305-0483(92)90003-P

Tamiz M, Jones DF (1996) Goal programming and pareto efficiency. J Inf Optim Sci 17:291-307. https:// doi.org/10.1080/02522667.1996.10699283

Tamiz M, Jones D, Romero C (1998) Goal Programming for decision making: an overview of the current state-of-the-art. Eur J Oper Res 111:569-581. https://doi.org/10.1016/S0377-2217(97)00317-2

Tanino T, Tanaka T, Inuiguchi M (eds) (2003) Multi-objective programming and goal programming: theory and applications. Springer, Berlin

Tretter M (2017) Standort- und Regionalentwicklung als strategische Aufgabe multinationaler Unternehmen: eine unternehmerische Perspektive auf regionale Zusammenhänge. Springer Gabler, Wiesbaden

Trzaskalik T, Michnik J (eds) (2002) Multiple objective and goal programming: recent developments. Physica, Heidelberg

United Nations, Department of Economic and Social Affairs (2018) World Urbanization Prospects 2018: highlights. https://population.un.org/wup/Publications/Files/WUP2018-Highlights.pdf. Accessed 11 Sep 2020

Vitoriano B, Romero C (1999) Extended interval goal programming. J Oper Res Soc 50:1280-1283. https://doi.org/10.1057/palgrave.jors.2600846 
Wagner-Endres S (2020) Kommunale Wirtschaftsförderung 2019: Strukturen, Aufgaben, Perspektiven: Ergebnisse der Difu-Umfrage. Difu Paper 2020, Berlin

Wallenius J, Dyer JS, Fishburn PC, Steuer RE, Zionts S, Deb K (2008) Multiple criteria decision making, multiattribute utility theory: recent accomplishments and what lies ahead. Manag Sci 54:13361349. https://doi.org/10.1287/mnsc. 1070.0838

Wang G, Qin L, Li G, Chen L (2009) Landfill site selection using spatial information technologies and AHP: a case study in Beijing, China. Environ Manag 90:2414-2421. https://doi.org/10.1016/j.jenvm an.2008.12.008

Xu J, Liu Q, Lei X (2016) A fuzzy multi-objective model and application for the discrete dynamic temporary facilities location planning problem. J Civ Eng Manag 22:357-372. https://doi.org/10.3846/ 13923730.2014.897974

Yu P-L (1985) Multiple-criteria decision making: concepts, techniques, and extensions. Springer, New York

Zimmermann H-J, Gutsche L (1991) Multi-criteria analyse: einführung in die theorie der entscheidungen bei mehrfachzielsetzungen. Springer, Berlin

Publisher's Note Springer Nature remains neutral with regard to jurisdictional claims in published maps and institutional affiliations.

\section{Authors and Affiliations}

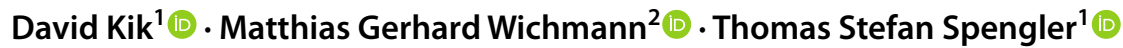

1 Institute of Automotive Management and Industrial Production, Chair of Production and Logistics, Technische Universität Braunschweig, Mühlenpfordtstraße 23,

38106 Braunschweig, Germany

2 Chair of Production Management, Chemnitz University of Technology, Thüringer Weg 7, 09126 Chemnitz, Germany 